\title{
Design and Fabrication of a Planar Three-DOFs MEMS-Based Manipulator
}

\author{
Boudewijn R. de Jong, Member, IEEE, Dannis M. Brouwer, Meint J. de Boer, Henri V. Jansen, \\ Herman M. J. R. Soemers, and Gijs J. M. Krijnen, Member, IEEE
}

\begin{abstract}
This paper presents the design, modeling, and fabrication of a planar three-degrees-of-freedom parallel kinematic manipulator, fabricated with a simple two-mask process in conventional highly doped single-crystalline silicon (SCS) wafers $\langle 100\rangle$. The manipulator's purpose is to provide accurate and stable positioning of a small sample $\left(10 \times 20 \times 0.2 \mu \mathrm{m}^{3}\right)$, e.g., within a transmission electron microscope. The manipulator design is based on the principles of exact constraint design, resulting in a high actuation-compliance combined with a relatively high suspension stiffness. A modal analysis shows that the fourth vibration mode frequency is at least a factor 11 higher than the first three actuation-related mode frequencies. The comb-drive actuators are modeled in combination with the shuttle suspensions gaining insight into the side and rotational pull-in stability conditions. The two-mask fabrication process enables high-aspect-ratio structures, combined with electrical trench insulation. Trench insulation allows structures in conventional wafers to be mechanically connected while being electrically insulated from each other. Device characterization shows high linearity of displacement wrt voltage squared over $\pm 10 \mu \mathrm{m}$ stroke in the $x$ - and $y$-directions and $\pm 2^{\circ}$ rotation at a maximum of $50 \mathrm{~V}$ driving voltage. Out-of-plane displacement crosstalk due to in-plane actuation in resonance is measured to be less than $20 \mathrm{pm}$. The hysteresis in SCS, measured using white light interferometry, is shown to be extremely small.

[2009-0254]
\end{abstract}

Index Terms-Compliant mechanism, electrostatic actuators, exact constraint design, multidegrees of freedom, nanometer positioning, precision engineering, trench isolation.

\section{INTRODUCTION}

$\mathbf{F}$ URTHER advances in nanotechnology demand for ultraprecision machines and instruments (with large throughput and reduced cycle time). These include various probe

Manuscript received October 23, 2009; revised May 18, 2010; accepted July 24, 2010. Date of publication September 15, 2010; date of current version October 1, 2010. This work was supported by the Innovative Oriented Research Program Precision Technology (Project IPT02308) of the Dutch Ministry of Economic Affairs. Subject Editor D. Elata.

B. R. de Jong was with MESA+ Institute for Nanotechnology, University of Twente, 7500 AE Enschede, The Netherlands. He is now with the Department of System in Package, Philips Applied Technologies, 5656 AE Eindhoven, The Netherlands (e-mail: boudewijn.de.jong@philips.com).

D. M. Brouwer is with the Department of Mechanical Automation, University of Twente, 7500 AE Enschede, The Netherlands (e-mail: d.m.brouwer@ ctw.utwente.nl).

M. J. de Boer, H. V. Jansen, and G. J. M. Krijnen are with MESA+ Institute for Nanotechnology, University of Twente, 7500 AE Enschede, The Netherlands (e-mail: m.j.deboer@ewi.utwente.nl; h.v.jansen@ewi. utwente.nl; g.j.m.krijnen@ewi.utwente.nl).

H. M. J. R. Soemers is with the Department of Mechanical Automation, University of Twente, 7500 AE Enschede, The Netherlands, and also with the Department of Mechatronics, Philips Applied Technologies, $5656 \mathrm{AE}$ Eindhoven, The Netherlands (e-mail: h.m.j.r.soemers@ctw.utwente.nl).

Color versions of one or more of the figures in this paper are available online at http://ieeexplore.iee.org.

Digital Object Identifier 10.1109/JMEMS.2010.2067196

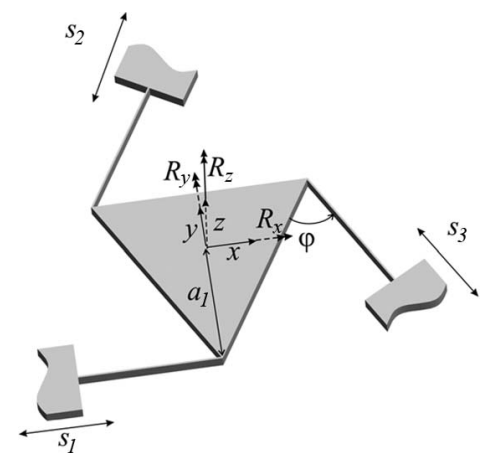

Fig. 1. Planar parallel manipulation concept, showing the three strokes $\mathrm{s} 1$ through $\mathrm{s} 3$ allowing the stage to be positioned in three DOFs $\left(x, y, R_{z}\right)$. The remaining DOFs $\left(R_{x}, R_{y}, z\right)$ are shown with dashed arrows; the mechanism is required to be stiff for forces acting in these directions. $\varphi$ is the angle between platform and plate spring.

techniques like atomic force microscopy, scanning tunneling microscopy or magnetic, thermal, and chemical reactive probes and also energy beam tools like UV optical, ion-beam, e-beam, and X-ray for structuring and scanning electron microscopy (SEM) and transmission electron microscopy (TEM) for characterization.

In this paper, we present the design, modeling, and fabrication of a three-degrees-of-freedom (DOFs) stage for precision positioning made using microelectromechanical systems (MEMS) technology with a simple two-mask fabrication process in a conventional $\langle 100\rangle$ wafer (concept shown in Fig. 1) [1]. Requirements for this device are strokes on the order of $20 \mu \mathrm{m}$, nanometer resolution and repeatability positioning, and a position stability of $1 \AA / \mathrm{min}$ reached within $1 \mathrm{~min}$. This last requirement demands stable operating temperature, very small absolute thermal expansion, and very low mechanical creep. The small size of MEMS and the mechanical properties of silicon are much in favor of meeting this requirement. Precision systems [2]-[4] potentially benefit from miniaturization. Not only does the size of devices decrease, but devices become faster, and greater functionality is offered in many cases [5]. Apart from general accuracy requirements, applications as discussed earlier all have their specific specifications. Here, these are left out of scope, but Brouwer et al., for instance, discuss a passive clamping mechanism for position stability of a combdrive-actuated micromanipulator in a TEM [6].

In recent publications, several multi-DOFs manipulators for accurate positioning with electrostatic actuators have been reported (see Table I). Jokiel et al. present various multiDOFs stages with rotary joints fabricated in a five-layer polySi process called SUMMiT-V [7]. Rotary joints enable large 
TABLE I

Overview of Recently Published Multi-DOF Manipulators for Accurate Positioning With Electrostatic Actuators

\begin{tabular}{|c|c|c|c|c|}
\hline Author & Mechanism* & Actuation & DOFs & Process \\
\hline Jokiel et al. [7] & $\begin{array}{l}\text { Rotary joints } \\
\text { PKM }\end{array}$ & $\begin{array}{l}\text { Electrostatic: } \\
\text { Comb-drive \& } \\
\text { Stepper }\end{array}$ & $\begin{array}{l}x, y, z(?, ?, ?) \\
R_{x}, R_{y}, z\left( \pm 5^{\circ}, \pm 5^{\circ}, 150 \mu \mathrm{m}\right)\end{array}$ & $\begin{array}{l}5 \text { layer poly } \mathrm{Si} \\
\text { SUMMiT-V }^{\mathrm{TM}}\end{array}$ \\
\hline Lu et al. [8] & $\begin{array}{l}\text { Flexible } \\
\text { PKM }\end{array}$ & $\begin{array}{l}\text { Electrostatic: } \\
\text { Comb-drive }\end{array}$ & $x, y( \pm 20 \mu \mathrm{m}, \pm 20 \mu \mathrm{m})(55 \mathrm{~V})$ & $\mathrm{SOI}$ \\
\hline Dong et al. [9] & $\begin{array}{l}\text { Flexible } \\
\text { PKM }\end{array}$ & $\begin{array}{l}\text { Electrostatic: } \\
\text { Comb-drive }\end{array}$ & $x, y(24 \mu \mathrm{m}, 24 \mu \mathrm{m})(180 \mathrm{~V})$ & SOI \\
\hline $\begin{array}{l}\text { Mukhopadhyay et al. } \\
{[10]}\end{array}$ & $\begin{array}{l}\text { Flexible } \\
\text { PKM }\end{array}$ & $\begin{array}{l}\text { Electrostatic: } \\
\text { Comb-drive }\end{array}$ & $x, y, R_{z}\left(18 \mu \mathrm{m}, 18 \mu \mathrm{m}, 1.7^{\circ}\right)(85 \mathrm{~V})$ & $\mathrm{SOI}$ \\
\hline Liu et al. [11] & $\begin{array}{l}\text { Flexible } \\
\text { PKM }\end{array}$ & $\begin{array}{l}\text { Electrostatic: } \\
(x, y) \text { Comb-drive } \\
(z) \text { parallel plate }\end{array}$ & $\begin{array}{l}x, y( \pm 12.5 \mu \mathrm{m}, \pm 12.5 \mu \mathrm{m})(30 \mathrm{~V}) \\
z(3.5 \mu \mathrm{m})(14.8 \mathrm{~V})\end{array}$ & $\begin{array}{l}\text { SOI device layer transferred } \\
\text { to pyrex }\end{array}$ \\
\hline Sarajlic et al. [12] & $\begin{array}{l}\text { Flexible } \\
\text { PKM }\end{array}$ & $\begin{array}{l}\text { Electrostatic: } \\
\text { Comb-drive }\end{array}$ & $x, y(?, ?)$ & $\begin{array}{l}\text { Dry release etching }+ \text { trench } \\
\text { isolation in bulk Si }\end{array}$ \\
\hline $\begin{array}{l}\text { De Jong et al. [1] and } \\
\text { this manuscript }\end{array}$ & $\begin{array}{l}\text { Flexible } \\
\text { PKM }\end{array}$ & $\begin{array}{l}\text { Electrostatic: } \\
\text { Comb-drive }\end{array}$ & $x, y, R_{z}\left( \pm 10 \mu \mathrm{m}, \pm 10 \mu \mathrm{m}, 2^{\circ}\right)(50 \mathrm{~V})$ & $\begin{array}{l}\text { Dry release etching }+ \text { trench } \\
\text { isolation in bulk Si }\end{array}$ \\
\hline
\end{tabular}

*PKM= Parallel Kinematic Mechanism

displacements but do not behave deterministically due to friction and play; therefore, other examples show flexible joints. A two-DOFs planar stage is presented by Lu et al. [8]. A twoDOFs planar stage with movable cantilever fabricated in silion on insulator (SOI) wafers is presented by Dong and Ferreira [9]. A parallel-kinematic three-DOFs planar manipulator fabricated in SOI wafers as well is reported by Mukhopadhyay et al. [10]. Liu et al. present a three-DOFs manipulator with two planar DOFs and one out-of-plane DOF [11]. A two-DOFs planar manipulation platform based on the same fabrication process as the device discussed in this paper is presented by Sarajlic et al. [12]. The platform is actuated by electrostatic comb-drives. The two DOFs of the planar manipulator are generated by a series coupling of movements of about $20 \mu \mathrm{m}$ in both directions.

The systems referred to earlier are fabricated by a bulk micromachining processes in single-crystalline silicon (SCS). Bulk micromachining enables high aspect-ratio structures, for example, leaf springs with a thickness of $2 \mu \mathrm{m}$ and a height of $40 \mu \mathrm{m}$. Such structures are required for planar stages with sufficient stiffness in the direction normal to the manipulation plane.

We present a planar three-DOFs parallel-kinematic stage specifically designed for stability and precision positioning. With the simple two-mask fabrication process, no SOI technology is required. The device shows high linearity and stability of displacement wrt voltage squared over $\pm 10 \mu \mathrm{m}$ stroke in the $x$ and $y$ directions and $\pm 2^{\circ}$ rotation at a maximum of $50-\mathrm{V}$ driving voltage.

\section{DESIGN}

The design of the three-DOFs planar manipulator is discussed. First, an overview is given of the geometry of the complete device, followed by the design of the plate springs between the actuators and the platform. Subsequently, the comb-drives are discussed including the negative electrostatic stiffness inside pull-in direction and the pull-in conditions for instability of an individual comb-tooth. Finally, the comb-drive suspension is treated with focus on the sideways and rotational pull-in conditions.

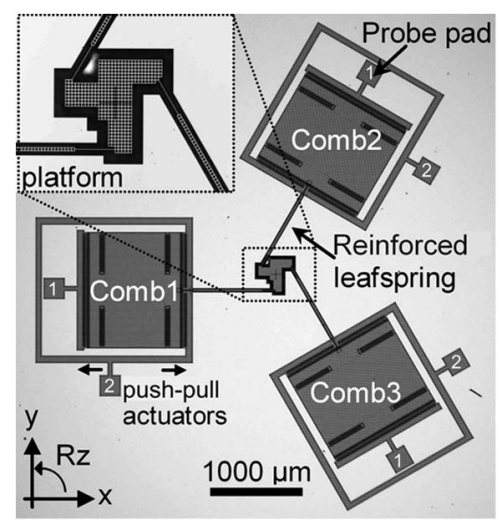

Fig. 2. Microscope image showing the top-view of a fabricated device. The comb-drives are numbered from 1 to 3 . Each comb-drive has two probe pads for push and pull actuation (common potential is the surrounding bulk). Dark gray areas are pierced by etch holes for device release and electrical isolation form the bulk. Inset: an enlargement of the platform.

\section{A. Geometry}

Fig. 2 shows a top-view of the fabricated three-DOFs manipulator. The particular process used for fabrication of this stage, as will be discussed in Section III, is based on a combination of high-aspect-ratio etching and dry isotropic release etching. The release step requires etch holes in all the structures that either are free-to-move or need to be electrically insulated. This implies that the shuttles for the comb-drives, the end-effector platform, and the paths of the electrical connection routing will all contain etch holes. For proper release of the shuttles and the platform, the etch holes should all have comparable sizes. The dark gray areas in Fig. 2 are in fact consisting of etch holes used for device release/undercut and electrical isolation from the bulk.

Three bidirectional comb-drives are arranged symmetrically around the end-effector platform and are connected to the platform by reinforced plate springs. Each comb-drive is numbered, and also the two probe pads for each comb-drive have there own number. Number 1 connects to the pull comb rack, while number 2 connects to the push comb rack. Electrical interconnect is accomplished by underetched regions (with etch holes) electrically insulated circumferentially by dielectric barriers. 


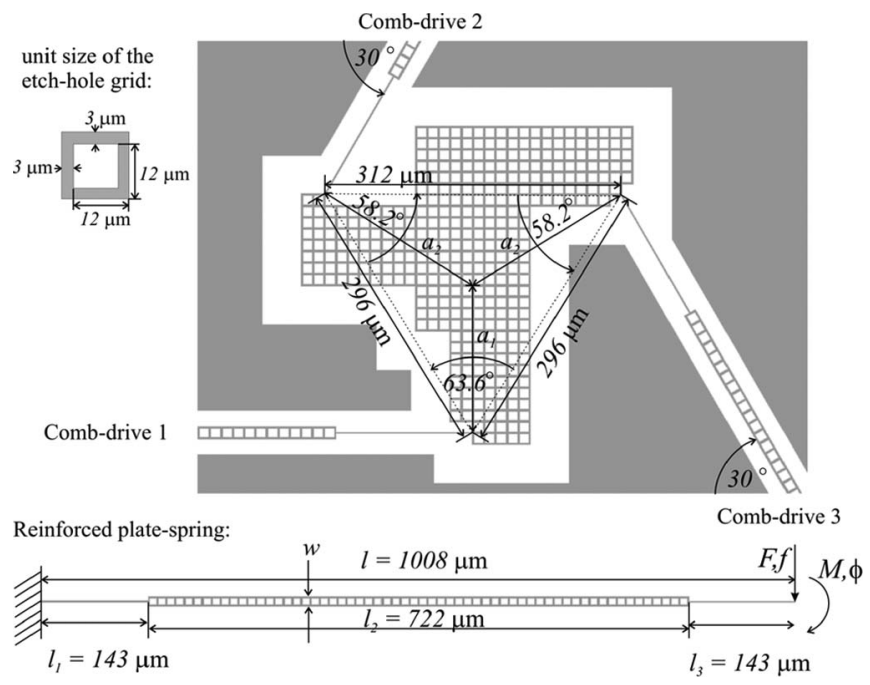

Fig. 3. Top-view of the design of the platform with dimensions and angles of the plate spring attached to the platform. To the side, a single-unit etch hole is shown, and in the lower part, one of the reinforced plate springs is shown with dimensions [ $w, l$, and $l_{1}$ to $l_{3}$ (meters)] and the definition of the force $F$ (newtons), deflection $f$ (meters), moment $M$ (newton-meters), and deflection angle $\mathrm{N}$ (radians).

These connection paths are found between the probe pads and the comb-drives. The comb shuttles are electrically connected to the grounded surrounding bulk $\mathrm{Si}$ via their suspension.

The inverse kinematic model for the mechanism, also known as a "3-PRR system" [13], can be derived. The first-order approximated transformation matrix between the position of the platform and the required strokes will be as follows:

$$
\left[\begin{array}{l}
s_{1} \\
s_{2} \\
s_{3}
\end{array}\right]=\left[\begin{array}{ccc}
1 & 0 & a_{1} \\
-\frac{1}{2} & -\frac{\sqrt{3}}{2} & a_{2} \\
-\frac{1}{2} & \frac{\sqrt{3}}{2} & a_{2}
\end{array}\right]\left[\begin{array}{c}
x \\
y \\
R_{z}
\end{array}\right]
$$

where $s_{1}$ to $s_{3}$ (meters) are the strokes of comb-drives 1 to 3 ; $a_{1}$ and $a_{2}$ (meters) are the arms from the platform center to the attachments of the plate springs (see Fig. 3); and $x, y$ (meters), and $R_{z}$ (radians) are the coordinates of displacements of the platform. Equation (1) is a purely kinematic coupling between the input $s_{1}$ to $s_{3}$ and the end-effector displacements and rotations. Geometric nonlinearities are not taking into account. However, the geometry changes very little, taking into account the $\pm 10 \mu \mathrm{m}$-limited comb-drive strokes compared to the endeffector size of about $300 \mu \mathrm{m}$.

\section{B. Plate Springs}

The plate springs are reinforced for robustness with respect to buckling (see Fig. 3) and to increase the stiffness of the relatively long arms in the direction perpendicular to the pane of movement [4]. The reinforcement has consequences for the stiffness matrix with respect to a prismatic plate spring. The consequences of the geometry on the stiffness matrix will be analyzed here.

Stiffness Matrix: First, a stiffness matrix is derived (see Appendix), relating the force $F$ (newtons) and moment $M$ (newton-meters) to the deflection $f$ (meters) and angle $\phi$ (radians) (see Fig. 3). The out-of-plane stiffness is not consid- ered here, since the consequences for out-of-plane stiffness do not relate to the force required to drive the manipulator. The reinforcement is considered rigid

$$
\left[\begin{array}{c}
M \\
F
\end{array}\right]=-\frac{1}{a\left(4 d-3 b^{2}\right)}\left[\begin{array}{cc}
\frac{4 E_{Y} I d}{l} & \frac{-6 E_{Y} I b c}{l^{2}} \\
\frac{-6 E_{Y} I b c}{l^{2}} & \frac{12 E_{Y} I c^{2}}{l^{3}}
\end{array}\right]\left[\begin{array}{l}
\varphi \\
f
\end{array}\right] .
$$

Equation (2) gives the stiffness matrix of the reinforced plate spring, where $E_{Y}$ (Pascals) is Young's modulus; and $I\left[\mathrm{~m}^{4}\right]$ is the moment of inertia of the thin plate spring parts. The matrix is derived with small deflections theory, allowing superposition of the equations for the deflection $f$ and the angle $\varphi$ for the different beam sections. The coefficients $a, b, c$, and $d$ are given by the following:

$$
\begin{aligned}
& a=p-1 \text { with } p=\frac{l_{2}}{l} \quad 0 \leq p<1 \\
& b=(p+1)(q-1)+2 \text { with } q=\frac{l_{1}}{l_{3}} \\
& c=q+1 \\
& d=a^{2}+c^{2}+p(p+1) q(q-1)+3 p q-1
\end{aligned}
$$

where $p$ and $q$ (see Fig. 3) respectively give the relative size and position of the reinforcement. Although (2) is strictly only valid for a flexure attached to a rigid support, analysis of the combdrive lateral stiffness (see Section II-D) shows that this stiffness is much larger than the plate spring stiffness.

Stage Compliance: The relative position and size of the reinforcement is chosen such that its compliance in the actuated directions of motion (relation between $f$ and $F$ for small deflections) is almost equal to that of a "normal" prismatic plate spring with a $6 / 7$ length. This is achieved for $p=5 / 7$ and $q=1$ [4]. These values can be derived with help of the stiffness matrix.

Rotational Compliance of the Stage: The reinforcement decreases the rotational compliance for in-plane rotations. Once an optimization criterion is chosen for the translational and rotational compliance, a different relative position $q$ and size of the reinforcement $p$ can be derived. Depending on the range of rotational and translational motions and the frequencies resulting from a modal analysis, $q$ can be optimized. According to (3), placing the reinforcement further away from the platform, $(q<1)$ will increase the rotational compliance and will decrease the translational compliance. Shortening the size of the reinforcement also leads to an increased rotational compliance, but at the cost of a decreased robustness.

A finite element analysis has been performed to determine the increased stiffness for in-plane rotations due to the pierced reinforcement with respect to prismatic plate springs, as shown in Fig. 3. It turns out that the stiffness the actuators experience is increased by $5.5 \%$ (Also, see Fig. 4).

\section{Comb-Drives}

The comb-drives are bidirectional, as shown in Fig. 5. In other words, at both sides of the shuttles, interdigitated racks of fixed and movable comb-drive teeth are situated. 


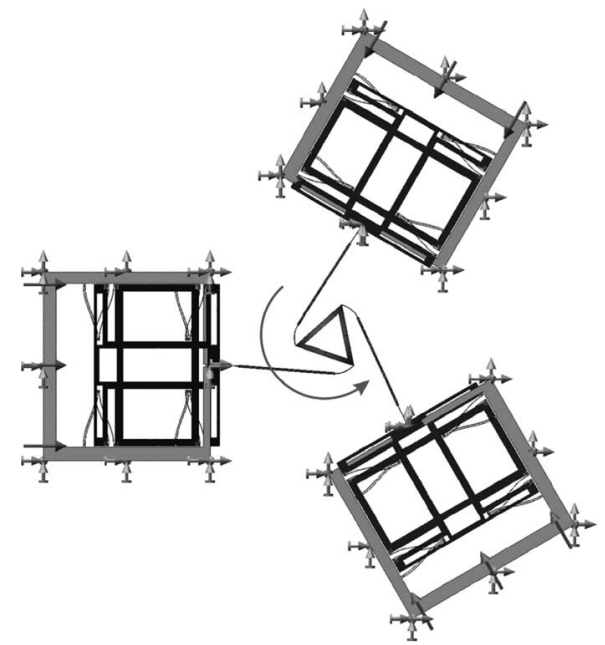

Fig. 4. Manipulator creates an $R_{z}$-rotation (indicated by the arrow) by actuating all three actuators radially inward or outward. Most of the deflection is concentrated in the leaf spring part connecting the reinforcement to the endeffector.

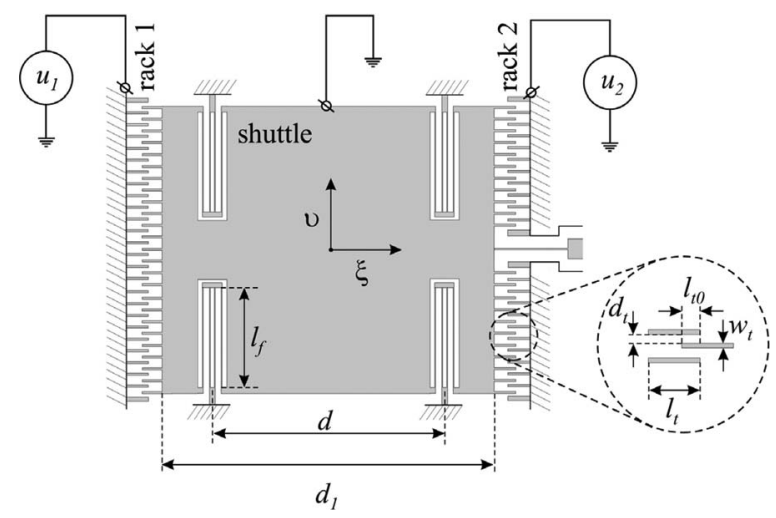

Fig. 5. Top-view of a comb-drive with an inset showing an enlargement of the comb-drive teeth. The shuttle is connected to the surrounding bulk by springs which also serve as contacts for the reference voltage. Voltage $u_{1}$ is applied to rack 1 , and voltage $u_{2}$ is applied to rack 2. Coordinates $v$ and $\xi$ are the local coordinates of the comb-drive.

The force each comb-rack can deliver as a function of the applied voltage is found by considering the following Legendre transform $\left[E_{i}^{*}\right.$ (joules)] of the energy $\left[E_{i}\right.$ (joules)] stored in the capacitances between the teeth $[i$ is comb-rack index 1 or 2 , and $q_{i}$ (coulombs) is the charge on a combtooth]:

$$
\begin{aligned}
d E_{i}^{*}\left(u_{i}, \xi, v\right) & =d E_{i}\left(q_{i}, \xi, v\right)-d\left(u_{i} q_{i}\right) \\
d E_{i}^{*}\left(u_{i}, \xi, v\right) & =F_{\xi, i} d \xi+F_{v, i} d v-q_{i} d v_{i} \\
E_{i}^{*}\left(u_{i}, \xi, v\right) & =E_{0}-\frac{1}{2} C_{i}(\xi, v) u_{i}^{2} .
\end{aligned}
$$

The forces $\left[F_{\xi, i}\right.$ (newtons)] delivered by the comb-drives are found by partial differentiation of $E_{i}$ (joules) with respect to $\xi$ (meters), while $u_{i}$ (volts) and $v$ (meters) are kept constant. $\gamma_{i}(-)$ defines the direction in which the comb-drive works and is equal to -1 for rack 1 and equal to 1 for rack 2

$$
\begin{aligned}
\text { inserting } C_{i}(\xi, v) & =n \varepsilon_{0} h_{t}\left(l_{t 0}+\gamma_{i} \xi\right)\left(\frac{1}{d_{t}+v}+\frac{1}{d_{t}-v}\right) \\
F_{\xi, i}\left(u_{i}, v\right) & =\left[\frac{\partial E_{i}^{*}\left(u_{i}, \xi, v\right)}{\partial \xi}\right]_{u_{i}, v} \\
& =\frac{\gamma_{i} n \varepsilon_{0} h_{t} u_{i}^{2}}{2}\left(\frac{1}{d_{t}+v}+\frac{1}{d_{t}-v}\right)
\end{aligned}
$$

The number of teeth pairs in the comb-drive racks $[n(-)]$ is 100. The spacing between the teeth $\left(d_{t}\right)$ is $4 \mu \mathrm{m}$, the width of a tooth $\left(w_{t}\right)$ is $2 \mu \mathrm{m}$, the height of the teeth $\left(h_{t}\right)$ is $37 \mu \mathrm{m}$, and the length of the teeth $\left(l_{t}\right)$ is $50 \mu \mathrm{m}$, with an initial overlap $\left(l_{t 0}\right)$ of $20 \mu \mathrm{m} . \varepsilon_{0}$ is the dielectric permittivity of vacuum; $8.854 \times$ $10^{-12} \mathrm{~F} / \mathrm{m}$.

Electrostatic Stiffness: The formula for the capacitance between the teeth, given in (5), shows a nonlinear dependence on the lateral position of the shuttle $(v)$. As a consequence, there is a nonlinear force buildup as a function of $v$. This force is responsible for the side pull-in instability of comb-drive actuators. The suspension of the comb-drive has to withstand this lateral force in the operation range of the comb-drives. In the next section, the lateral suspension will be analyzed by comparing the suspension stiffness with the lateral electrostatic stiffness of the comb-drive. The electrostatic stiffness of each comb-drive is found by partially differentiating $E_{i}^{*}$ twice with respect to $v$ under the condition of constant $u_{i}$ and $\xi$ as follows:

$$
\begin{aligned}
c_{e l, i}\left(u_{i}, \xi, v\right) & =\left[\frac{\partial^{2} E_{i}^{*}\left(u_{i}, \xi, v\right)}{\partial v^{2}}\right]_{u_{i}, \xi} \\
& =-n \varepsilon_{0} h_{t} u_{i}^{2}\left(l_{t 0}+\gamma_{i} \xi\right)\left(\frac{1}{\left(d_{t}+v\right)^{3}}+\frac{1}{\left(d_{t}-v\right)^{3}}\right) .
\end{aligned}
$$

According to Bochobza-Degani et al. [14], charge control is proven to always result in a larger displacement range for electrostatic actuators than voltage control. However, applying charge control to a comb-drive results to a highly nonlinear relation between electrostatic force in the $\xi$-direction and charge. Balancing the electrostatic force with a linear spring force results in a charge displacement relation that is very nonlinear as well. Such a system is ill suited for accurate positioning.

Comb-Tooth Failure: A comb-drive tooth has a limited individual stiffness. As a result, instability can also occur due to compliance of a tooth. Elata and Leus presents the following relation for the side pull-in of an individual comb tooth [15]:

$$
\tilde{u}_{p i}^{2}=24 \frac{\varepsilon_{0} l_{t}^{4}}{E_{Y}^{\prime} w_{t}^{3} d_{t}^{3}} u^{2}, \quad \text { with } \quad E_{Y}^{\prime}=\frac{E_{Y}}{1-\nu^{2}} .
$$

Here, $u_{p i}$ is the normalized pull-in voltage depending on the relative overlap of the comb-teeth. The minimal value given for the normalized $u_{p i}$ is 3.516. Furthermore, $E_{Y}$ (Pascals) is Young's modulus, and $\nu$ is Poisson's ratio. Assuming that the Young's modulus of silicon is $130 \mathrm{GPa}$, and the Poisson's ratio is 0.27 , the pull-in voltage for instability of an individual 
comb-tooth for the given dimensions is found to be about $0.8 \mathrm{kV}$ (The assumed Young's modulus is the minimum of the crystal-orientation-dependent Young's modulus, and the Poisson's ratio is the maximum of the crystal-dependent Poisson's ratio in the plane of a $\langle 100\rangle$ wafer [16]).

The instability analysis for side pull-in and rotational pullin of the entire shuttle due to shuttle suspension compliance is given in the next sections. Shuttle pull-in is expected to occur at lower values of the driving voltage than tooth pull-in due to the relatively short teeth.

Linear Drive: The bidirectional configuration allows linear driving of the comb-drives with respect to the applied voltage, whereas the voltage-force relation for a single comb-drive is quadratic. The linear operation is accomplished by applying equal dc voltages $\left[U_{\mathrm{dc}}\right.$ (volts) $]$ to both comb-drive racks and adding a voltage related to the desired displacement [ $u$ (volts)] to the side where the shuttle should be attracted to and subtracting the same voltage at the other side. The resulting force dependence of the voltages is shown in (8) as follows:

$$
\Sigma F_{\xi}=F_{\xi, 2}+F_{\xi, 1} \propto\left(U_{\mathrm{dc}}+u\right)^{2}-\left(U_{\mathrm{dc}}-u\right)^{2}=4 U_{\mathrm{dc}} u .
$$

Linear drive can mean an important improvement for nanometer-resolution positioning. Without linear drive, the voltage source should be variable and stable over a large range. Moreover, the larger the voltage applied, the more sensitive the position is for voltage variations. These requirements are much easier to realize.

The principle of linear drive is based on totally equal combdrives. In practice, there might be a difference between the comb-drives. In that case, the forces for both comb-drives will be proportional to (considering the possibility of different $U_{\mathrm{dc}}$ and $u$ for racks 1 and 2 and proportional control factors $p_{1}$ and $p_{2}$ ) as follows:

$$
\begin{aligned}
& F_{\xi, 1} \propto p_{1}\left(U_{\mathrm{dc}, 1}+u_{1}\right)^{2}=p_{1}\left(U_{\mathrm{dc}, 1}^{2}+2 U_{\mathrm{dc}, 1} u_{1}+u_{1}^{2}\right) \\
& F_{\xi, 2} \propto p_{2}\left(U_{\mathrm{dc}, 2}-u_{2}\right)^{2}=p_{2}\left(U_{\mathrm{dc}, 2}^{2}-2 U_{\mathrm{dc}, 2} u_{2}+u_{2}^{2}\right) .
\end{aligned}
$$

For linear drive, the following conditions need to hold:

$$
\begin{aligned}
p_{1} U_{\mathrm{dc}, 1}^{2} & =p_{2} U_{\mathrm{dc}, 2}^{2} \\
p_{1} u_{1}^{2} & =p_{2} u_{2}^{2}
\end{aligned}
$$

which is satisfied once $U_{\mathrm{dc}, 2}=\sqrt{p_{1} / p_{2}} U_{\mathrm{dc}, 1}$ and $u_{2}=$ $-\sqrt{p_{1} / p_{2}} u_{1}$. These conditions can relatively easily be accomplished in electronics.

\section{Shuttle Suspension}

The shuttle of the comb-drive is suspended by four folded flexures (see Fig. 6). This suspension is overconstrained; just two folded flexures would be enough to constrain all DOFs except the driving direction. However, since the device is monolithic and the uniformity of the processing is high on the scale of the device dimensions, this practically does not lead to undeterministic behavior, as evidenced by many wellperforming examples, e.g., [1], [12], [17] (although additional

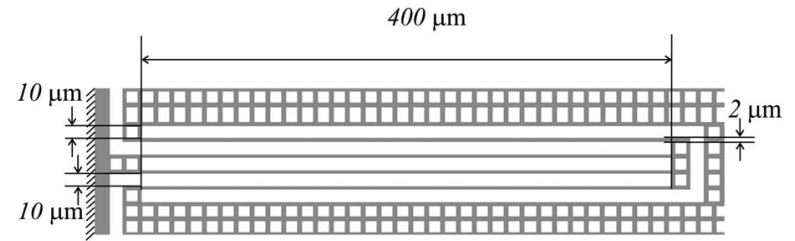

Fig. 6. Top-view of one of the folded flexures that suspend the comb-drive shuttle, including design dimensions.

characterization on the nanometer scale should verify the exact effect of the overconstrained suspension on the linearity of the force-displacement relation).

According to the principle of exact constrained design [4], [18], [19], ideally, the suspension has zero stiffness in the actuation direction, while it has to be infinitely stiff in all other DOFs. Achieving relatively small stiffness in actuation direction is limited by the minimum feature size in lithography and the desired minimum stiffness in other directions. Later, an analysis will follow of the suspension stiffness in the various DOFs, and especially, the side and rotational pull-in conditions will be analyzed.

Actuation Stiffness: The first-order model for the actuation stiffness of one folded flexure is (where $I_{\zeta}\left[\mathrm{m}^{4}\right]$ is the area moment of inertia about the out-of-plane $\zeta$-axis) [20], [21] as follows:

$$
c_{f, \xi}=12 \frac{E_{Y} I_{\zeta}}{l_{f}^{3}}=\frac{E_{Y} h_{f} t_{f}^{3}}{l_{f}^{3}} .
$$

Because of the nature of a folded flexure, initially, almost no stiffening in actuation direction occurs, since the plate springs in the folded flexure are free to shorten. At a shuttle displacement of $28 \%$ of the plate spring length, the folded flexure has stiffened by $5 \%$ [22]. Therefore, (11) provides a suitable model for small displacements for the following dimensions of the plate springs, namely: the length $\left(l_{f}\right)$ is $400 \mu \mathrm{m}$, the thickness of a plate spring $\left(t_{f}\right)$ is $2 \mu \mathrm{m}$, and the height $\left(h_{f}\right)$ is $37 \mu \mathrm{m}$. Inserting these values in (11) and multiplying by four (the shuttle is suspended by four folded flexures) results in a value for the suspension stiffness in the $\xi$-direction of $2.4 \mathrm{~N} / \mathrm{m}$. With help of (5), the required voltage to be applied to one of the comb-racks for a $10-\mu \mathrm{m}$ displacement is calculated to be $53 \mathrm{~V}$.

In-Plane Translational Suspension Stiffness: The first-order model for the in-plane suspension stiffness in the undeflected state of one folded flexure is [20], [21]

$$
c_{f, v}=\frac{E_{Y} A}{l_{f}}=\frac{E_{Y} t_{f} h_{f}}{l_{f}}
$$

where $A\left[\mathrm{~m}^{2}\right]$ is the cross-sectional area of the plate spring. Equation (12) only holds true for deflections on the order of the thickness of the plate spring [21]. Van Eijk and Legtenberg have modeled two different situations for the deflected plate springs [21], [23]. These two situations are shown in Fig. 7 (top) and (bottom). Van Eijk considers a deflected straight-guided beam fixed for additional deflections and loaded by a force $F_{v}$ (newtons) [Fig. 7 (top)], while in Legtenberg's model, additional deflection is allowed [Fig. 7 (bottom)]. Brouwer notices that 


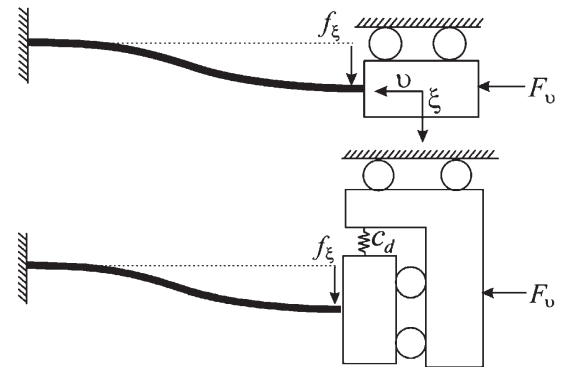

Fig. 7. Two cases of a force $F_{v}$ loading a deflected plate spring. Plate spring deflected, but fixed for additional movement in the (top) $\xi$-direction, deflected plate spring free to move in both the (bottom) $\xi$ - and $v$-directions.

the first situation often does not apply to MEMS because the stiffness of the drive system is generally low [24]. Brouwer takes into account that stiffness $c_{d}$ (newtons/meter) is finite. He presents simulation results obtained with SPACAR [25] for the stiffness in the in-plane suspension direction depending on the beam's deflection for various values of $c_{d}$, including infinite and zero. The notion that $c_{d}$ is infinite coincides with Van Eijk's model, and that $c_{d}$ is zero coincides with the Legtenberg's model. To illustrate the difference between both situations, the stiffness reduction factors resulting from both models are given in (13) and (14)

$$
\delta_{1}(\xi)=\frac{c_{f, v}(\xi)}{c_{f, v}(0)}=\left(1+\frac{12}{700}\left(\frac{\xi}{2 t_{f}}\right)^{2}\right)^{-1} .
$$

The first model [see (13)] predicts a stiffness reduction factor $\left[\delta_{1}(-)\right]$ of $10 \%$ in case of a deflection over thickness ratio of $2.5(5-\mu \mathrm{m}$ deflection for each plate spring in case of a $10-\mu \mathrm{m}$ stroke).

The second model predicts an enormous stiffness decrease of $90 \%$ for a total folded flexure displacement of $10 \mu \mathrm{m}$. The stiffness reduction factor resulting from the second model $\left[\delta_{2}(-)\right]$ is as follows:

$$
\delta_{2}(\xi)=\frac{c_{f, v}(\xi)}{c_{f, v}(0)}=\left(1+\frac{9}{25}\left(\frac{\xi}{2 t_{f}}\right)^{2}\right)^{-1} .
$$

A side pull-in analysis is performed for the case of $c_{d}$ is zero for a bidirectional comb-drive operating in linear drive [see (8)]. This is a worst-case scenario.

The following expression (giving the absolute value of the electrostatic stiffness over the lateral stiffness) is plotted for different values of $U_{\mathrm{dc}}$ (volts) against $u / u_{\max }$, where $u_{\max }$ is the value for $u$ for a displacement of $10 \mu \mathrm{m}$ at the given value of $U_{\mathrm{dc}}$ :

$$
\left|\frac{c_{e l}(\xi)}{4 \delta_{2}(\xi) \cdot c_{f, v}}\right|, \quad \text { with } \quad \xi=\frac{F_{\xi}\left(u, U_{d c}\right)}{c_{f, \xi}}
$$

where $c_{e l}$ is the electrostatic stiffness as given in (6).

The plot is shown in Fig. 8 for $v=0 \mu \mathrm{m}$ and for the following $U_{\mathrm{dc}}$ values: $30,50,100$, and $480 \mathrm{~V}$. The linearity of the linear drive benefits from a large $U_{\mathrm{dc}}$ value; however, the plot shows that for a value of $480 \mathrm{~V}$, the electrostatic stiffness exceeds the mechanical stiffness in the $v$-direction, causing side pull-in. $U_{\mathrm{dc}}$ does not need to be as high as $480 \mathrm{~V}$. A $U_{\mathrm{dc}}$ value

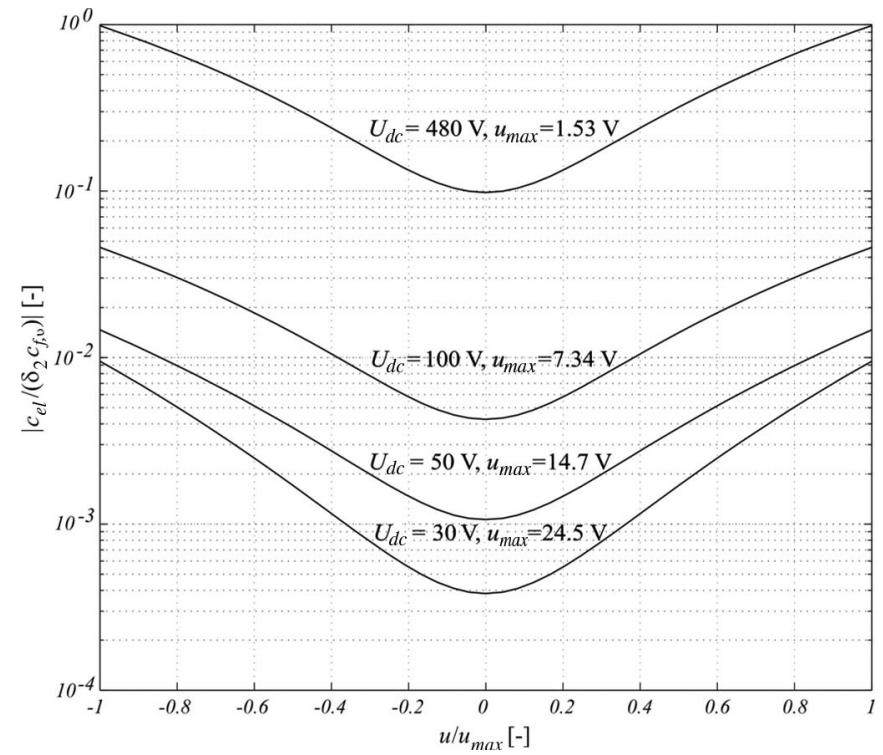

Fig. 8. Equation(15) plotted against $u / u_{\max }$ for different values for $U_{\mathrm{dc}}$. $u_{\max }$ is the voltage $u$, where the stroke is $10 \mu \mathrm{m}$; this value is different for each different value of $U_{\mathrm{dc}}$. When $U_{\mathrm{dc}}$ is $480 \mathrm{~V}$, the electrostatic stiffness equals the shuttle suspension stiffness in the $v$-direction (pull-in situation) for the maximum stroke of $10 \mu \mathrm{m}$ at $u=u_{\max }$.

up to $100 \mathrm{~V}$ will certainly be enough, and the design leaves a large enough margin for increased displacements and/or extra force to drive an external load. However, another type of instability, rotational pull-in, is still to be analyzed to draw a final conclusion about the safe operating conditions.

In-Plane Rotational Suspension Stiffness: The rotational electrostatic stiffness about the center point of the comb-drive shuttle is equal to $k_{e l}=c_{e l}\left(d_{1} / 2+l_{t}\right)^{2}$, where $d_{1}$ (meters) is the length of the shuttle, as shown in Fig. 5, acting as arm for the force $F_{v}$ to exert a moment around the symmetric center of the shuttle. It is assumed the shuttle will rotate around this point, because the comb-drive forces and the suspension are both symmetric with respect to this point for zero position of the shuttle. The rotational stiffness of the suspension evaluated around the center of the shuttle is calculated as follows:

$$
k_{f}(\xi)=4 \delta_{2}(\xi) c_{f, v}\left(\frac{d}{2}\right)^{2}
$$

To analyze the rotational pull-in, the following expression is plotted in a similar way as was done for the side pull-in:

$$
\left|\frac{k_{e l}(\xi)}{k_{f}(\xi)}\right|, \quad \text { with } \quad \xi=\frac{F_{\xi}\left(u, U_{\mathrm{dc}}\right)}{c_{f, \xi}} .
$$

Fig. 9 shows the plot of the stiffness ratio for $v=0 \mu \mathrm{m}$ and for the following $U_{\mathrm{dc}}$ values: $30,50,100$, and $320 \mathrm{~V}$. Clearly, the device is more sensitive to rotational pull-in than to side pull-in. Rotational pull-in occurs at $U_{\mathrm{dc}}=320 \mathrm{~V}$. Like for the case of side pull-in, $U_{\mathrm{dc}}$ values up to $100 \mathrm{~V}$ can be considered safe. Following from the rotational pull-in analysis as well, additional stroke and/or external loading are possible within the safety margins for this suspension design. 


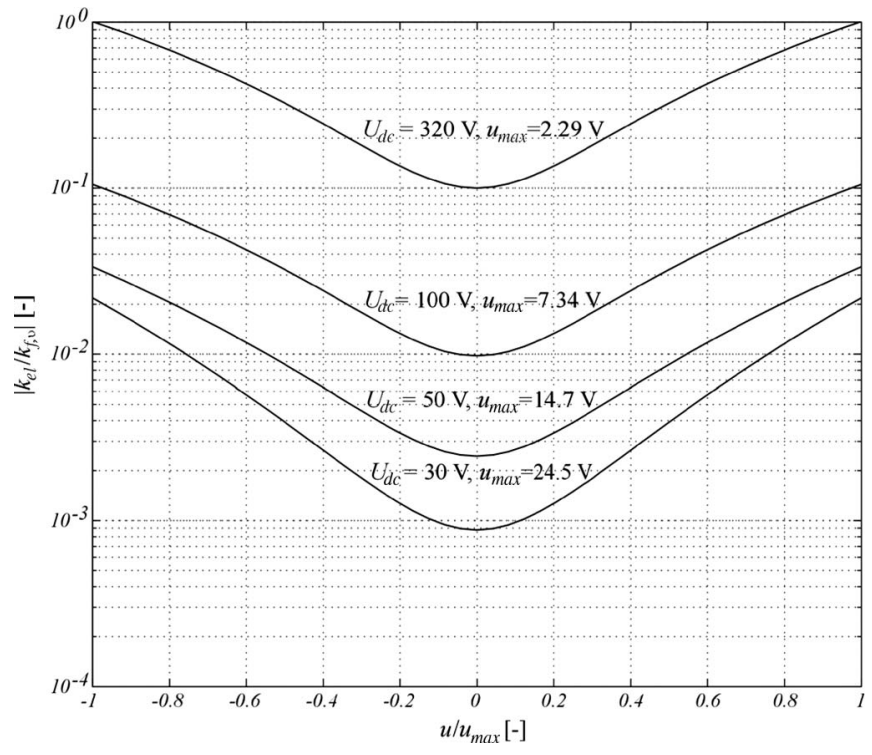

Fig. 9. Equation(17) plotted against $u / u_{\max }$ for different values for $U_{\mathrm{dc}}$. $u_{\max }$ is the voltage $u$, where the stroke is $10 \mu \mathrm{m}$; this value is different for each different value of $U_{\mathrm{dc}}$. When $U_{\mathrm{dc}}$ is $320 \mathrm{~V}$, the rotational electrostatic stiffness equals the rotational shuttle suspension stiffness (pull-in situation) for the maximum stroke of $10 \mu \mathrm{m}$ at $u=u_{\max }$.

Out-of-Plane Stiffness: The first-order out-of-plane suspension stiffness at the free end of one of the leaf springs in a folded flexure is given by [20]

$$
c_{\zeta}=12 \frac{E_{Y} I_{\xi}}{l_{f}^{3}}=\frac{E_{Y} t_{f} h_{f}^{3}}{l_{f}^{3}}
$$

where $I_{\xi}\left[\mathrm{m}^{4}\right]$ is the area moment of inertia about the $\xi$-axis.

For a length-over-height ratio of more than ten, the suspension stiffness in the $\zeta$-direction is practically constant up to deflection-to-thickness ratios of ten [22]. In each folded flexure, two series of plate springs are placed in parallel. In other words, $c_{\zeta}$ (newtons/meter) for one folded flexure is equal to equation (18). The total out-of-plane stiffness of the shuttle suspension is four times the value of one folded flexure, resulting in $0.82 \times$ $10^{3} \mathrm{~N} / \mathrm{m}$. This can be considered relatively stiff, compared to the electrostatic forces expected in the device pulling the shuttle down if the base and the suspended structures are grounded. Due to the much larger gap, the isotropic under etch technology provides between the device layer and the base compared with a SOI wafer, electrostatic pull down and liquid adhesive film buildup leading to stiction is much less of an issue here.

Discussion of Assumptions: The pull-in analysis does not give rise to concern for typical driving conditions of the combdrive. The design even allows larger displacements and significant external loading, without risking pull-in. This is backed by the experience in the experimental situation, where no pullin was observed for typical operation. However, in the stiffness analysis, the intermediate bodies of the folded flexure have been assumed rigid. In reality, these have limited stiffness and are pierced by square-shaped etch holes for the device release. The exact contribution to the compliance of the total suspension is analyzed by a modal finite element method (FEM) simulation in the next section.

\section{E. Modal Analysis of the Manipulator}

A modal analysis is provided to verify if exact constraint design has led to the preferred situation where the frequencies of the actuation related modes are low with respect to the suspension mode frequencies. The actuation related modes are the modes which result in the $x$ and $y$ translations and $R_{z}$ rotation of the end-effector. The analysis is performed in Cosmos Works. To simulate anisotropic SCS, Young's and shear moduli of each of the leaf springs have been input separately. Because the real manipulator has many etch holes, the model has been simplified to enable calculations. However, near each plate spring end, etch holes with the real dimensions have been inserted to model the extra compliance of the bodies due to the etch holes.

Table I shows a comparison between a prismatic, a solid reinforced, and a pierced reinforced plate spring version of the manipulator. The effective thickness of all the plate springs in the FEM model is set at $1.75 \mu \mathrm{m}$ to agree with the measurements presented in Section IV. In all cases, modes 1-3 show (see Fig. 10 for the first mode) the actuation related modes which should have a low frequency because the actuation suspension should preferably be compliant. Modes 4-6 (see Fig. 10 for the fourth mode) of the prismatic version show the internal vibration modes of the prismatic plate springs. This can be effectively alleviated by reinforcing the plate springs, which increases the vibration mode frequency to more than the first seven shown in Table II. Mode 7 of the prismatic plate spring version shows an out-of-plane bending mode, which is almost equal to the fourth modes of the reinforced versions (see Fig. 10). The difference between a pierced and a solid reinforced plate spring version is not large. In this case, the pierced reinforced plate springs even result in improved performance over solid reinforced plate springs. The design can be further optimized by reducing the mass of the shuttles. The modal analysis shows that the fourth vibration mode frequency is at least a factor 11 higher than the first three mode frequencies which shows the effectiveness of the exact constraint design approach.

\section{FABRICATION}

The planar manipulator is fabricated with a simple twomask process that enables high-aspect-ratio structures made in highly doped SCS combined with electrical insulation [26]. With the help of trenches refilled with a dielectric material, the process allows structures in conventional $\langle 100\rangle$ wafers to be mechanically connected, while being electrically insulated from each other. Insulation from the bulk and release of freeto-move structures is performed by dry isotropic etching. A generic functional structure is shown in Fig. 11.

\section{A. Process Flow}

Fig. 12 shows the process overview. The process starts with a highly doped $(p+)\langle 100\rangle$ wafer. Into a layer of Olin 907-17 resist, the mask for the 2- $\mu \mathrm{m}$-wide insulation trenches is transferred. The trenches are etched to a depth of $40 \mu \mathrm{m}$ by advanced 
$1^{\text {st }}$ mode prismatic beams $(1.25 \mathrm{kHz})$
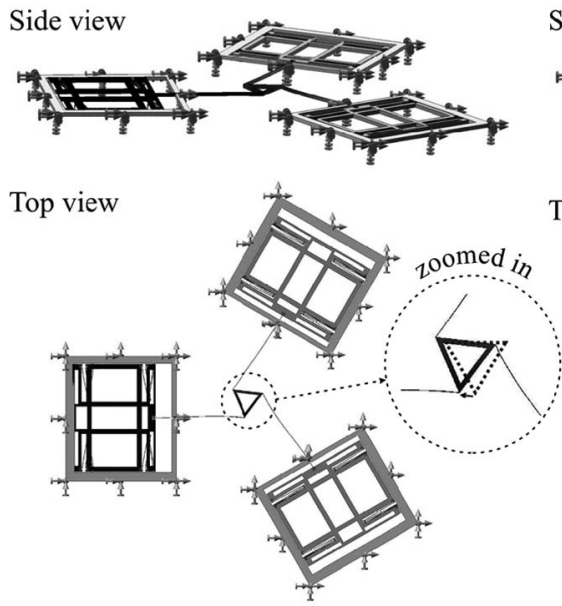

$4^{\text {th }}$ mode prismatic beams $(13.5 \mathrm{kHz})$

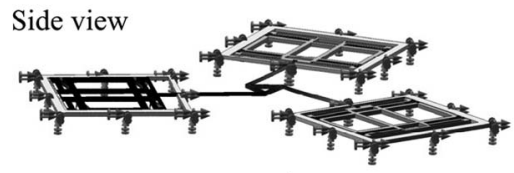

Top view

$4^{\text {th }}$ mode reinforced and pierced plate springs $(16.1 \mathrm{kHz})$

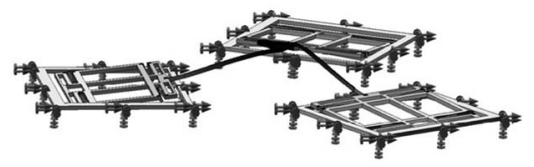

Fig. 10. Results for the modal finite-element analysis of the manipulator for Modes 1 and 4 for the model with prismatic beams between comb-drives and platform and for Mode 4 for the model with reinforced and pierced plate springs between comb-drives and platform.

TABLE II

First Vibration Mode Frequencies of the Manipulator For SeVERAl Design Variations in KiloherTZ

\begin{tabular}{llll}
\hline $\begin{array}{l}\text { Vibration } \\
\text { Mode }\end{array}$ & $\begin{array}{l}\text { Prismatic } \\
\text { plate-springs }\end{array}$ & $\begin{array}{l}\text { Solid reinforced } \\
\text { plate-springs }\end{array}$ & $\begin{array}{l}\text { Pierced } \\
\text { reinforced } \\
\text { plate-springs }\end{array}$ \\
\hline 1 & 1.25 & 1.25 & 1.25 \\
2 & 1.35 & 1.34 & 1.35 \\
3 & 1.42 & 1.47 & 1.47 \\
4 & 13.9 & 15.5 & 16.1 \\
5 & 15.1 & 19.9 & 19.9 \\
6 & 15.2 & 21.4 & 21.4 \\
7 & 16.2 & 21.7 & 21.7 \\
\hline
\end{tabular}

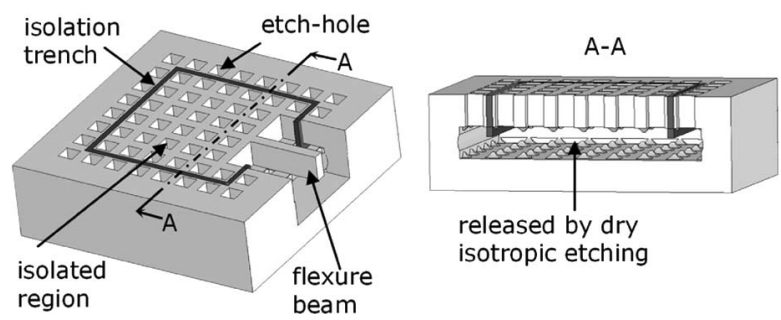

Fig. 11. Generic functional structure to describe the functionalities that can be achieved with the fabrication process. To the right a region in is shown with etch holes for release from the bulk, a flexure beam for use in a flexible mechanism and an isolation trench filled with SiRN to define electrically isolated regions. To the left, cross-section A is shown exposing the released structure with etch holes.

silicon or Bosch etching with an Adixen SE100 plasma etch system.

Next, the resist is stripped in a barrel etcher $\left(\mathrm{O}_{2}\right.$ plasma $)$, and the fluor carbon sidewall protection is ashed in an oxidation (a)

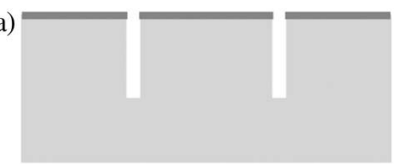

(c)

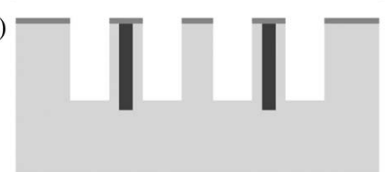

(e)
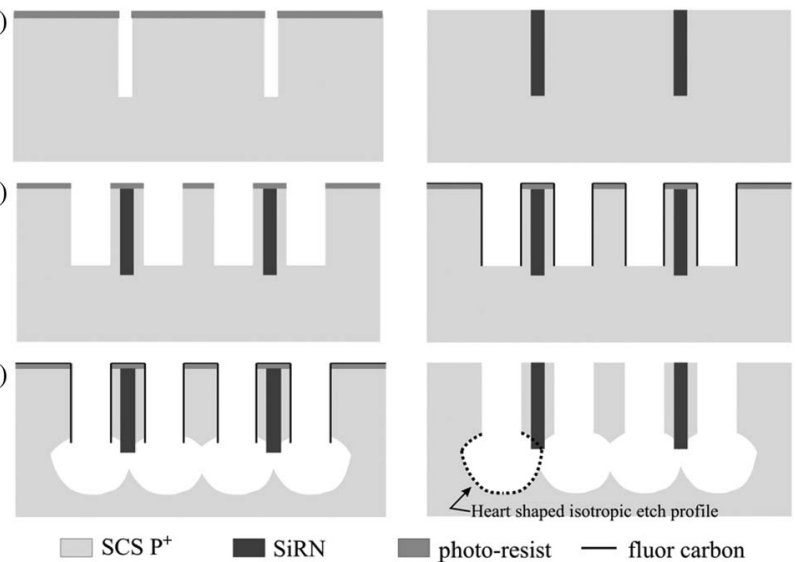

(b)
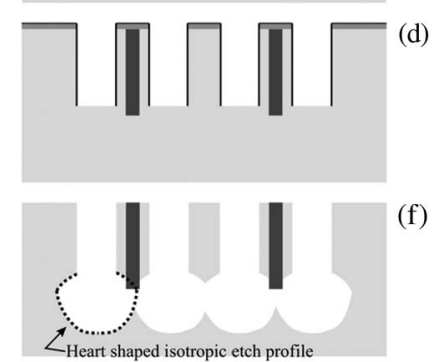

(f)

Fig. 12. Process used for the three-DOFs manipulator [11]. (a) Dry etching of isolation trenches, (b) filling of isolation trenches with SiRN, (c) dry etching of mechanical structure including etch holes, (d) sidewall protection with fluor carbon, (e) dry isotropic under etching, and (f) the final result with indication of the heart shaped isotropic etch profile.

oven at $800{ }^{\circ} \mathrm{C}$ (remaining oxide is etched in 50\% HF), as shown in Fig. 12(a). Subsequently, the trenches are filled with low-stress low-pressure chemical vapor deposition silicon-richsilicon-nitride $(\mathrm{SiRN})$, and the $\mathrm{SiRN}$ is removed from the topside by dry etching, as shown in Fig. 12(b). The second mask, defining the device structures, is transferred into an Olin 907-17 resist layer, and the uncovered silicon is etched to a depth of $37 \mu \mathrm{m}$ by Bosch etching with an Adixen SE100 plasma etch system, as shown in Fig. 12(c). The wafer remains inside the reactor, and an extra layer of fluor carbon is applied covering the complete trench. The bottom of the trench is selectively removed by a directional etch step, as shown in Fig. 12(d). Still keeping the wafer inside the reactor, the process conditions are switched to isotropic etching with SF6. This step releases the 
device and electrically insulates the device layer from the rest of the wafer, as shown in Fig. 12(e). Finally, the resist is stripped in an oxide plasma, and the fluor carbon is ashed, as shown in Fig. 12(f).

\section{B. Process Issues}

Some remarks ought to be made with respect to the design rules for this process. The etch rate $(\mu \mathrm{m} / \mathrm{min})$ of the Bosch process is dependent, among other things, on the size and shape of the mask openings, e.g., etching a larger opening proceeds faster than etching a smaller opening. Furthermore, the etch rate in an outstretched opening will be larger compared to the rate in a square etch hole of equal width. This effect is known as loading and is caused by the difference in exposed Si [27]. Also, the difference in aspect-ratio (ARDE) has influence on the resulting etch depth [27], [28]. The effect, for some part, is caused by difference in diffusion of the etching agent toward the bottom of the trench and can be weakened by reducing the overall etch rate lessening the significance of transport, or by applying more fluor carbon. In the latter case, use is made of the fact that more fluor carbon is deposited in large openings thus primarily reducing the etch rate in these openings. However, ARDE cannot be completely canceled. Therefore, the width of the openings should not show a large spread to make sure the isotropic release starts everywhere at more or less the same depth, and the release is successful.

The isotropic release produces etch profiles with a more or less heart shape. The shape and size is again dependent on the size of the trench or hole from which the release starts. In larger sized trenches or holes, the profile often shows a slight dependence on the crystal orientation [as shown in Fig. 12(e) and (f)]. What matters for the success of the process is that the beams are undercut. This means that the radius of the profile requires being large enough in the horizontal direction. However, the duration of the underetch is limited by the erosion of the fluor carbon protecting the sidewalls of the structures. When the fluor carbon is completely eroded, the formerly protected structures are damaged.

Finally, to succeed in electrical insulation, the SiRN-refilled trenches need to extend beyond the released $\mathrm{Si}$ structures. Hereto, the etch depth of the device structures (mask 2) has to be considerably less than the depth of the insulation trenches. For this device, the insulation trenches extend up to a depth of $40 \mu \mathrm{m}$, and the rest of the device structure extends up to a depth of $37 \mu \mathrm{m}$. A similar reasoning holds for the lateral extent of the insulation trenches beyond the Si grid structures. A margin should be taken into account for the alignment error between the first and second mask. The fabrication rules for the insulation tranches is further discussed by Brouwer et al. [6].

\section{Consequences of Geometry on Beam Mechanics}

The process discussed earlier allows the manufacturing of plate-spring-like beams. Many parameters are involved in the process that influence the resulting beam geometry. In Fig. 13, a schematic cross-section is shown with parameters defining

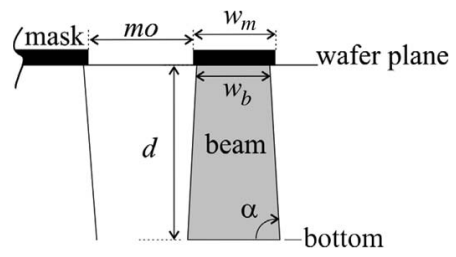

Fig. 13. Schematic cross section of the beam geometry after dry etching with indication of its characteristic geometric features.

the beam geometry. The height of the beam is represented by the etch depth $d$ (meters), and the width of the beam is given by $w_{b}$ (meters). The width of the mask defining the beam is $w_{m}$ (meters), and the size of the mask opening is mo (meters). $\alpha$ (radians) represents the angle of the beam sidewall with its bottom.

The width of the beam $\left(w_{b}\right)$ is determined by lithography, erosion of the mask during etching, and the dry etching process itself (in this case, Bosch etching). The conditions during lithography determine the resulting width of the photoresist mask $\left(w_{m}\right)$. A mask always erodes during etching. Other mask materials could be used that are more resistant; however, this means the resist pattern should be transferred into another layer. This also introduces deviations of $w_{m}$ with respect to the design width. The Bosch etching process parameters determine the amount of underetch, while the cyclic nature of the Bosch process causes for a scallop structure in the beam walls. While designing the beam, the deviation and spread in the design width should be considered, especially with respect to the desired lateral stiffness of the beam. This value is heavily determined by the beam width.

The height of the beam [ $d$ (meters)] is determined by the dry etching process conditions and the shape and size of the mask openings (as mentioned earlier). The exact profile of dry isotropic release process is yet hard to predict, causing additional uncertainty with respect to the exact height of the resulting beam. For the mechanical behavior of the plate spring, the height is of lesser importance. However, there should not be too much variations in the etch depths $(d)$ of the structures to be released by the isotropic etch since these results in obstructions for moving parts of the device.

The tapering of the beam $(\alpha)$ is determined by the etch process conditions and the shape and size of the mask openings at either side of the beam. With the tapering, the cross-section of the beam loses symmetry. The intended rectangular crosssection turns into a trapezium shape. Mechanically, this results in crosstalk in the direction perpendicular to the intended direction of deflection of the beam.

\section{Characterization}

This section discusses the profile, due to lithography, found in the width of the plate springs and the measurements of the platform displacement by pattern recognition.

\section{A. Plate Spring Geometry}

The width of the beams of the platform suspension and the folded flexures is taken as small as possible to reduce 


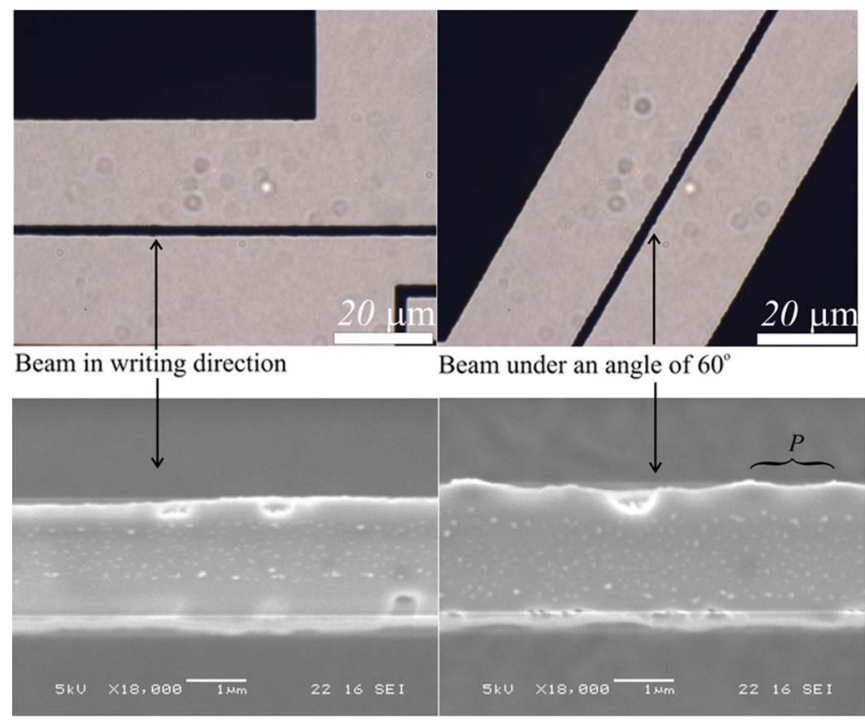

Fig. 14. Microscope images showing the (top row) masks and (bottom row) SEM images of a beam in writing direction (left) and a beam under an angle of $60^{\circ}$ (right).

the stiffness of the suspensions in their compliant directions and eventually to reduce the required voltage and size of the actuators. The limitations to the attainable smallest feature sizes are the mask, the required resist thickness, and the achievable aspect ratio of the beams with Bosch etching. A feature size of $2 \mu \mathrm{m}$ is achievable where it concerns the resist and the etching, but the mask shows a significant variation of up to $10 \%$ on the width of the beams. This has a large effect on the in-plane stiffness of the beams. The mask consists of a glass plate with a chromium layer. The chromium is structured by a lithographic process and is protected by a photoresist in which the mask patterns are written by a laser. This laser is scanned over the mask, and it writes dots to build up the pattern. In case mask openings for the beams are oriented under an angle with respect to the laser, the spatial frequency of the width variation increases, as shown in Fig. 14. The resolution of the mask features can be improved if electron-beam writing is applied; however, this is a lot more expensive.

The profile shows some periodicity as shown in Fig. 14 by $P$. However, it is not entirely regular and symmetric with respect to the center-plane along the length of the beam. Furthermore, it is not sure how far the profile extends over the height of the beams. Since the stiffness of the beam for bending in the plane of the wafer is depending on the beam thickness to the third power, the actual stiffness might show a large deviation from the designed stiffness. Because the profile cannot simply be fitted in an analytic expression (mainly due to lack of symmetry), a worst-case stiffness deviation will be calculated. For a beam width of $2 \mu \mathrm{m}$ with a variation in the width of $10 \%$, the worst-case ratio between the moment of inertia for a $10 \%$ increase $(2.2 \mu \mathrm{m}$ thickness) and the moment of inertia for a $2-\mu \mathrm{m}$ thickness would be 1.33 . This means a deviation of the design stiffness of $33 \%$ (for a decrease of $10 \%$ this ratio is 0.73 resulting in a $27 \%$ deviation). This is a large overestimation since it assumes a beam width of $2.2 \mu \mathrm{m}$ over the complete length of the beam. If a cosine profile is assumed, a lower limit for the stiffness variation can be found with an effective moment of inertia value as follows:

$$
I_{\text {eff }}=\frac{h}{24 \pi} \int_{0}^{2 \pi}\left(w-\epsilon w \cos l^{\prime}\right)^{3} d l^{\prime}
$$

where $w$ is the beam width of $2 \mu \mathrm{m} ; \epsilon$ [-] is the amplitude variation of 0.1 ; and $h$ is the beam height of $37 \mu \mathrm{m}$. Dividing $I_{\text {eff }}$ by the moment of inertia for the design values results in a ratio of 1.02 . The lower limit for the stiffness variation is $2 \%$. It will be hard to model the effect of the profile exactly. If no other means of mask writing is used, these deviations should be taken into account when designing flexure mechanisms. There are no indications that the general mechanical behavior of flexures is influenced undesirably. Furthermore, the extent of the profile over the beam height requires additional characterization.

\section{B. Displacement Measurements}

Applied Method: With help of the inverse kinematic model, the three bidirectional comb-drives are powered in the correct proportion to each other to move the platform to a certain position and give it a certain rotation. However, the model does not provide the absolute voltage required for a given displacement, since it does not include any information about stiffness and applied forces; it is purely geometrical. To know the voltage required for a certain displacement, the displacement of a comb-drive is measured in relation to the applied voltage (no linear driving is applied, i.e., no dc bias voltage is used). This calibration results in an approximately linear relation between the displacement and the voltage squared.

Knowing the displacement-voltage relation, the platform is moved along the $x$ - and $y$-axis and rotated about the $z$-axis. The positions are measured with help of National Instruments Vision Assistant 7.1 [29]. Pictures are taken of the platform in each position also showing the fixed surrounding. With pattern recognition, based on correlation, the relative position between the fixed surrounding and the platform is determined. The pattern recognition is calibrated by counting the number of pixels spanning the length of a row of etch holes found in the device. The period of the etch holes is $12 \mu \mathrm{m}$; thus, by counting the number of pixels spanning the length of ten etch holes, the number is related to micrometers by dividing it by 120 . This results in $0.34 \mu \mathrm{m}$ per pixel for a picture resolution of $1280 \times$ 960 pixels. The pattern recognition also outputs the orientation of the recognized pattern. This orientation provides the rotation about the $z$-axis. The measurement error is determined by measuring the distance between two points with a fixed distance to each other for 28 times and determining the standard deviation of the results.

The relation found between the driving voltage and the displacement of a single comb-drive shuttle is as follows: $\xi(U)=$ $3.4 \times 10^{-3} U^{2} \mu \mathrm{m}$, where $U$ (volts) is the voltage applied to one of both comb-racks; while the other remains at zero volt. The voltages applied to the comb-drives range from 0 to $50 \mathrm{~V}$. Since the displacement is related to the square of the applied voltage, the square root should be taken of the relations between 

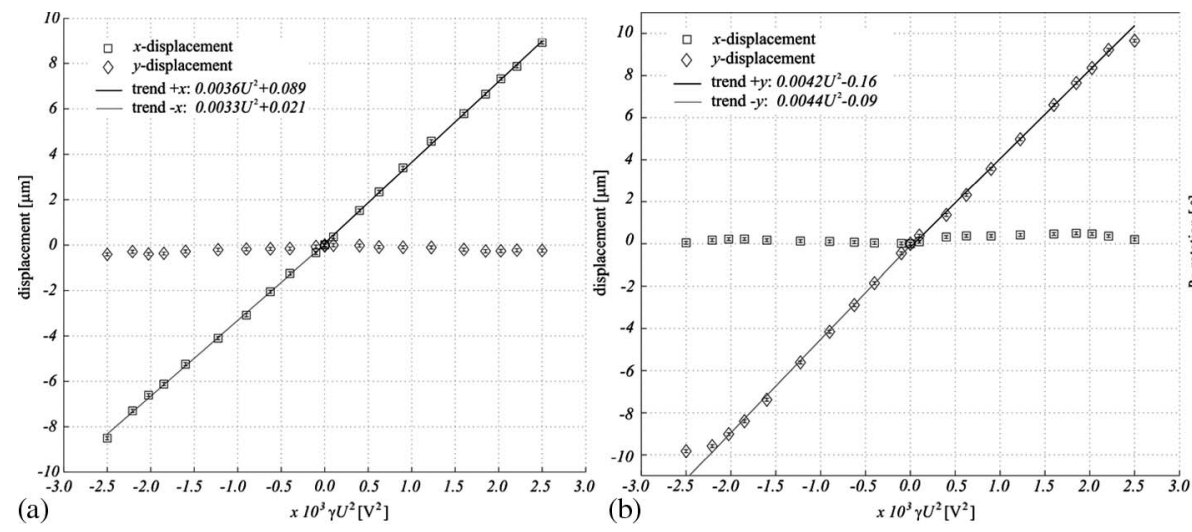

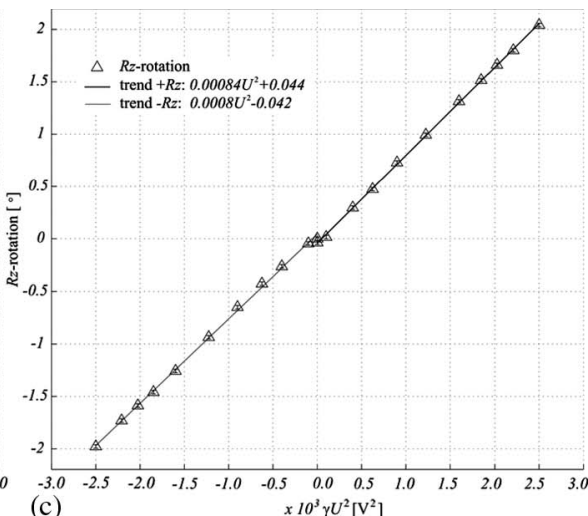

(c)

Fig. 15. Graphs of the measurements of the displacements in $x$ - and $y$-direction and of $R_{z}$-rotation as a function of the squared voltage. Graphs (a) and (b) both show the measurement points for the displacements and crosstalk together with trendlines for the displacements in positive and negative direction. Graph (c) shows the $R_{z}$-rotation together with trendlines for positive and negative rotation.

the three comb-drives given in the inverse kinematic model, e.g., the voltages for moving along the positive $x$-axis will be $U$ for rack 2 of comb-drive 1 and $1 / \sqrt{ } 2 U$ for rack 1 of combdrives 2 and 3 (see Fig. 2).

Measurement Results: Fig. 15 shows three graphs of the measurements of the displacement in the $x$ - and $y$-direction and of $R_{z}$-rotation as a function of the squared voltage. Negative values for $U^{2}$ indicate displacement in opposite direction. Furthermore, for the voltage along the horizontal axes, a choice has to be made concerning which of the voltages applied to the comb-drives is given. For displacement in the $x$-direction, the voltage applied to comb-drive 1 is given. In case of displacement in the $y$-direction, the voltage applied to comb-drive 3 is given. For rotation about the $z$-axis, there is no difference between the voltages applied to the comb-drives.

The measurement points given in the graphs show error bars equal to the standard deviations evaluated as discussed earlier. For the $x$ - and $y$-displacement, the error is $\pm 0.07 \mu \mathrm{m}$, while for the $R_{z}$-rotation, the error is $\pm 0.02^{\circ}$. For the displacement graphs, measurement points of the crosstalk in the orthogonal direction are given as well. Trendlines are given for the $x$ - and $y$-displacement and the $R_{z}$-rotation for the positive and the negative direction separately.

Predominantly, the results show a very encouraging behavior of the manipulator that closely matches the expected linear relation between the displacements and rotation with respect to the squared driving voltages. The graphs show two types of deviations from the inverse kinematic model used to (coarsely) determine the required driving voltages. First, the crosstalk toward translation or rotation not directed in the intended driving direction. Although not shown in the graphs because of presentation issues, crosstalk to $R_{z}$-rotation for the $x$ - and $y$-displacement having an average of $0.02^{\circ}$ with a maximum of $0.16^{\circ}$.

Furthermore, displacement crosstalk for $R_{z}$-rotation was found as well, having an average of $-0.02 \mu \mathrm{m}$ and a maximum of $0.8 \mu \mathrm{m}$. The second deviation is found in the trendlines, showing a different slope for $x$ - and $y$-displacements of the platform in positive and negative direction.

The main reason for crosstalk concerns the fact that the inverse kinematic model does not take into account compliance in the mechanism. More particularly, the fact that Young's modulus depends on the orientation of the flexures in the $\langle 100\rangle$ silicon wafer is not taken into account. The matrix linearized approach only holds true for small deformations because geometric nonlinearities are not taken into account. Additionally, the profile due to the mask writing as discussed in the previous section is not represented in that model. Finally, geometric imperfections cause differences between the actual manipulator behavior and the inverse kinematic model.

Apparently a difference in force in positive and negative directions of the comb-drives does not lead to significant results related to the measurement accuracy. The found difference in trendlines might result from the relatively small number of measurement points.

\section{Out-of-Plane Crosstalk}

In-plane movements may be accompanied with out-of-plane crosstalk. Possible reasons for this crosstalk are asymmetry of the suspension beam's cross-section with respect to the height axis and in-plane beam orientations not parallel to one of the main crystal directions of the silicon crystal.

To measure possible out-of-plane crosstalk for in-plane movements, scanning laser Doppler vibrometry through a microscope is applied. This vibrometry is part of the MSA-400 Micro System Analyzer from Polytec [30] and is able to scan over a surface to visualize vibration modes of the measured surface. Furthermore, it is equipped with a reference laser beam, which function allows selecting a reference point and distinguishing between the vibrations of the object to be measured and the vibrations of its substrate and determining the relative phase of the vibration. Vibrometry is a very sensitive method; this particular system has a displacement resolution of at least $0.4 \mathrm{pm} / \sqrt{ } \mathrm{Hz}$.

Applied Method: The crosstalk out-of-plane vibration component for in-plane movement is measured for two devices. One device is a single bidirection comb-drive identical to the comb-drives in the three-DOFs manipulator and oriented along the $\langle 100\rangle$ crystal direction. The second device is a comb-drive oriented along an in-plane angle of $60^{\circ}$ with respect to the $\langle 100\rangle$ direction. This actuator is part of the 
manipulator; thus, it is loaded by the platform and the other two comb-drives.

During the measurement, the driving frequency of the combdrive is scanned, and for each frequency value, the out-of-plane velocity and the phase are measured. This results in a frequency spectrum with peaks at the frequencies of the vibration modes. The velocity data can be used by the software to calculate the displacement enabling a plot of the displacement versus frequency. Since the comb-drives are compliant for in-plane displacement, the in-plane vibration is expected in the lower frequency range, while the higher frequency modes are either out-of-plane modes of the complete shuttle or plate vibration modes within the shuttle. The assumed in-plane resonance is compared to the calculated resonance frequency and an inplane displacement measurement is performed with the Planar Motion Analysis also part of the MSA-400 Micro System Analyzer.

The software allows defining multiple points on the device to be measured. The points are connected in a mesh to form a surface that is animated to show the vibration modes. Although a reference beam can be applied, it only compares the vibrations of two points. Since the substrate is a thin plate, nonrigidly attached to the measurement chuck, the wafer plane shows vibrations, and one single point is not sufficient for reference. Therefore, apart from defining a mesh of points on the shuttle of the comb-drive, an extra mesh is defined on the "fixed" surrounding. Once a peak is found in the measured frequency spectrum, the animation is used to check if the shuttle vibrates significantly more than the surrounding area, before deciding the peak is a vibration of the shuttle.

The comb-drive actuators are driven asymmetrical (only one of both comb-racks is powered) by a periodic chirp with an amplitude of $6 \mathrm{~V}$ and an offset of $3 \mathrm{~V}$. The offset prevents a frequency doubling of the shuttle movement with respect to the driving signal; however, the movement will still show some harmonic distortion.

Measurement Results: Fig. 16 shows the out-of-plane displacement measurement results obtained with the vibrometer. The graph shows multiple peaks at 1074, 1163, and $1414 \mathrm{~Hz}$. The first three vibration modes are in good agreement with the calculated modes by FEM in Section II if the effective thickness of all the plate springs in the FEM model is set at $1.75 \mu \mathrm{m}$. The calculated resonance frequency for a single comb-drive moving in-plane is found by the following:

$$
f_{r}=\frac{1}{2 \pi} \sqrt{\frac{4 c_{\xi}}{m_{s}}}, \quad \text { with } \quad m_{s}=\rho f A_{s} h_{s}
$$

Where, the stiffness $c_{\xi}$ (newtons) is given in (11); $m_{s}$ (kilograms) is the mass of the shuttle; $\rho$ is the density of Si of $2330 \mathrm{~kg} / \mathrm{m}^{3}$; and $f[-]$ is the fill-factor equal to $9 / 12$ compensating for the etch holes. The shuttle surface $A_{s}$ is $1.035 \times 106 \mu \mathrm{m}^{2}$, and the shuttle height $h_{s}$ is $37 \mu \mathrm{m}$. These values result in a resonance frequency of $1249 \mathrm{~Hz}$. This value is near to the values found with the laser vibrometer. The deviation is expected since the shuttle height, the folded flexure

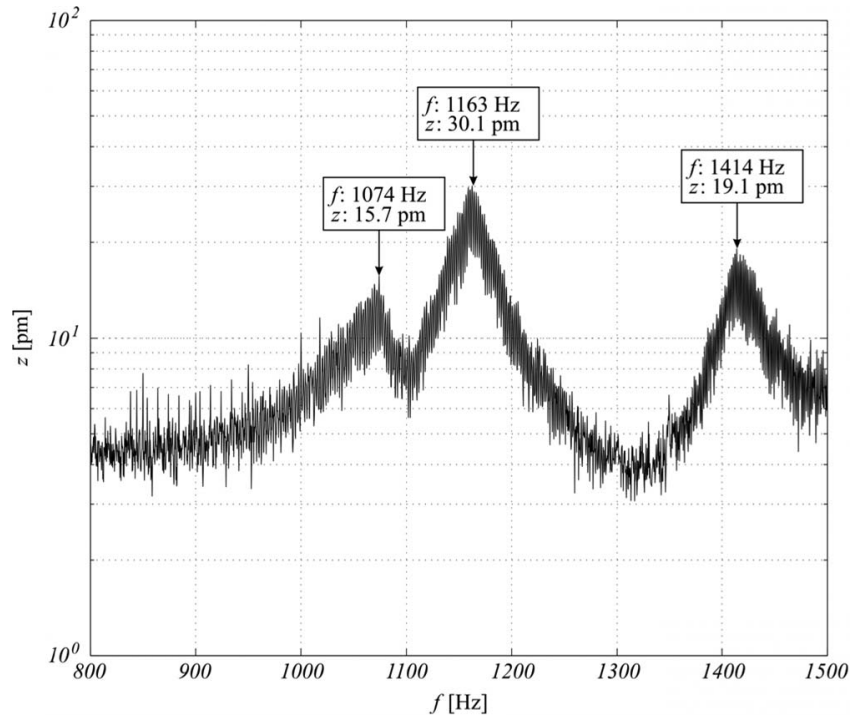

Fig. 16. Vibrometer measurement results showing the out-of-plane displacement spectra for the comb-drive oriented along an angle of $60^{\circ}$ with respect to the $\langle 100\rangle$ direction. Peaks are visible at 1074, 1163, and $1414 \mathrm{~Hz}$.

beam thickness, and the fill-factor cannot be determined very accurately due to process variations.

For the single comb-drive, the in-plane displacement is measured at its resonance frequency of $1433 \mathrm{~Hz}$ and for a driving voltage with amplitude of $6 \mathrm{~V}$ and an offset of $3 \mathrm{~V}$ as used with the vibrometer. With an in-plane displacement amplitude of $1 \mu \mathrm{m}$, the out-of-plane displacement amplitude at resonance of the first and second comb-drive, respectively, are 19.8 and $19.1 \mathrm{pm}$. This is very small. Also, the displacements found at the two other peaks in Fig. 16 are not significant. The manipulation can clearly be regarded planar within less than $1 \mathrm{~nm}$ movement in out-of-plane direction.

\section{Hysteresis Indication}

Material hysteresis is a possible cause of virtual play in a flexible mechanism and compromises high resolution positioning. SCS is known for having very low hysteresis as can be expected from a single crystalline material, since it has no domain walls that can shift due to loading. Furthermore, the silicon wafers are very pure (except doping) and have very little crystal defects. However, highly doped wafers (as used here) by definition do have impurities due to boron doping. To qualitatively characterize silicon structures with respect to hysteresis, an underetched test structure consisting of a 37- $\mu \mathrm{m}$-thick plate with a mesh of etch holes is loaded by a probe needle. With the white-light interferometric topographic profiler of the MSA-400 Micro System Analyzer, the topography of the test surface is measured before, during, and after the loading.

Fig. 17 shows the topographies obtained by white-light interferometry. The profile of the loaded mesh in Fig. 17(b) shows that the loading by the probe needle causes an indentation of $0.6 \mu \mathrm{m}$ (note the differences in $z$-scale). The loading has been applied for at least $10 \mathrm{~min}$. As shown in Fig. 17(c), after the loading was removed, the profile shows a nanometer scale indentation. However, this is hardly significant and could be 


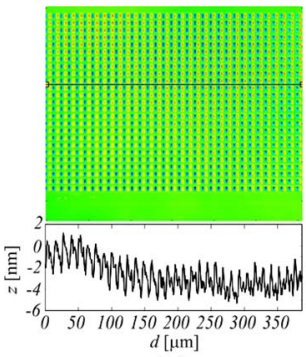

(a)

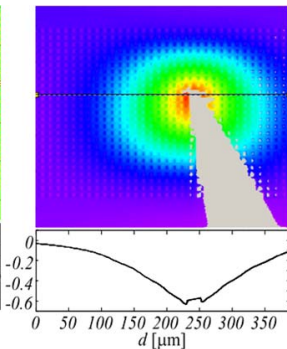

(b)

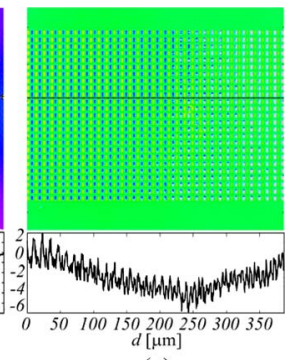

(c)
Fig. 17. Image showing the (top) topography and the (bottom) profile along the line in the topography for the grid (a) before, (b) during, and (c) after indentation with a probe needle. Notice the difference in scale in (b).

resulting from surface damage due to the probe needle. This experiment shows that material hysteresis in a highly doped $\mathrm{p}^{+}$SCS wafer is of no significance for nanometer resolution positioning.

\section{CONCLUSION}

A precision stage for three-DOFs precision positioning has been designed, modeled, and fabricated based on a simple twomask fabrication process. The manipulator design is based on the principles of exact constraint design, resulting in a high actuation compliance combined with relatively high suspension stiffness. Therefore, the modal analysis shows that the fourth vibration mode frequency is at least a factor 11 higher than the first three mode frequencies.

Measurements have shown that applying a simple first-order inverse kinematic model leads to relatively accurate feedforward positioning of the platform. Furthermore, the expected linear relation between the driving voltage squared and the platform displacements and rotation is verified to large extend by the measurements. Although, the measurement method does not allow accurate measurement of displacements on the nanometer scale, the linear behavior of the system is very promising for nanometer resolution positioning. From the mechanical point of view, the flexure-based friction-free mechanism together with a low hysteresis material like SCS enables nanometer resolution. The hysteresis was qualitatively characterized by indentation and white-light interferometry not resulting in any significant memory effect. The bottleneck for nanometer resolution positioning will be the stability of the voltage source used to drive the actuators. Applying linear drive can largely reduce the demands on the voltage sources used for driving.

The suspension of the comb-drives is analyzed with respect to side and rotational pull-in. It was found that rotational pull-in occurs at the lowest driving voltage. In case of voltage supply in linear drive mode at a shuttle displacement of $10 \mu \mathrm{m}$, rotational pull-in occurs at a dc voltage of $320 \mathrm{~V}$. The stiffness model takes into account the large decrease of the suspension with deflection. This form of nonlinear modeling is shown to be very important for a good indication of the stiffness under deflection. During operation of the comb-drive, no pull-in has occurred; however, no voltages in the expected pull-in range have been applied. The compliance contribution of the square-shaped etch holes has been researched by FEM analysis. Plate springs using

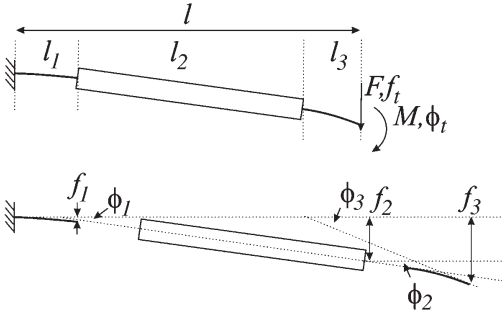

Fig. 18. Schematic of the reinforced flexure and the definition of the partial deflections and partial angular deflection.

a pierced reinforcement result in improved performance over solid reinforced plate springs.

With the help of laser doppler vibrometry, out-of-plane crosstalk has been measured for in plane displacement of the comb-drives in resonance. The measured out-of-plane crosstalk for an in-plane displacement with an amplitude of $1 \mu \mathrm{m}$ was on the order of $20 \mathrm{pm}$. The manipulation can clearly be regarded planar with far less than 1-nm displacement in out-of-plane direction.

\section{APPENDIX}

The stiffness matrix for the reinforced plate spring, as shown in Fig. 18, is derived with help of the standard equation for the deflection $[f$ (meters) $]$ and the angle $[\phi$ (radians) $]$ at the end of a beam as a function of the applied force [ $F$ (newtons)] and moment $[M$ (newton-meters)] at the end of a beam [31] as follows:

$$
\begin{aligned}
& f(M, F)=\frac{M L^{2}}{2 E_{Y} I}+\frac{F L^{3}}{3 E_{Y} I} \\
& \phi(M, F)=\frac{M L}{E_{Y} I}+\frac{F L^{2}}{2 E_{Y} I} .
\end{aligned}
$$

The standard relations are based on the assumption that Hooke's law is valid and the deflections are small relative to the thickness of the beams. Additionally this assumption allows the use of superposition. Accordingly, the total deflection $\left[f_{t}\right.$ (meters) $]$ and the angle $\left[\phi_{t}\right.$ (radians)] at the end of the reinforced plate spring is obtained by the following:

$$
\begin{aligned}
& f_{t}(M, F)=f_{3}(M, 0)+f_{3}(0, F) \\
& \phi_{t}(M, F)=\phi_{3}(M, 0)+\phi_{3}(0, F) .
\end{aligned}
$$

First, $f_{3}(M, 0)$ and $\phi_{3}(M, 0)$ are calculated for the case of $F=0$ as follows:

$$
\begin{aligned}
f_{3}(M, 0) & =f_{2}+\phi_{2} l_{3}+\frac{M l_{3}^{2}}{2 E_{Y} I} & \phi_{3}(M, 0) & =\phi_{2}+\frac{M l_{3}}{E_{Y} I} \\
f_{2}(M, 0) & =f_{1}+\phi_{1} l_{2} & \phi_{2}(M, 0) & =\phi_{1} \\
f_{1}(M, 0) & =\frac{M l_{1}^{2}}{2 E_{Y} I} & \phi_{1}(M, 0) & =\frac{M l_{1}}{E_{Y} I}
\end{aligned}
$$

where $E_{Y}$ is Young's modulus; and $I$ is the moment of inertia, both equal for parts 1 and 3 . The reinforcement, part 2, is assumed to be fully rigid. 
Second, $f_{3}(0, F)$ and $\phi_{3}(0, F)$ are calculated for the case of $M=0$ as follows:

$$
\begin{array}{ll}
f_{3}(0, F)=f_{2}+\phi_{2} l_{3}+\frac{F l_{3}^{3}}{3 E_{Y} I} & \phi_{3}(0, F)=\phi_{2}+\frac{F l_{3}^{2}}{2 E_{Y} I} \\
f_{2}(0, F)=f_{1}+\phi_{1} l_{2} & \phi_{2}(0, F)=\phi_{1} \\
f_{1}(0, F)=\frac{F l_{1}^{3}}{3 E_{Y} I}+\frac{M_{F} l_{1}^{2}}{2 E_{Y} I} & \phi_{1}(0, F)=\frac{F l_{1}^{2}}{2 E_{Y} I}+\frac{M_{F} l_{1}}{E_{Y} I}
\end{array}
$$

where $M_{F}$ is the moment at the end of beam part 1 as a result of the force $F$ multiplied by the arm $l_{2}+l_{3}$. In other words, $M_{F}=F\left(l_{2}+l_{3}\right)$

$$
\left[\begin{array}{l}
\phi \\
f
\end{array}\right]=-a\left[\begin{array}{cc}
\frac{l}{E_{Y} I} & \frac{b l^{2}}{2 c E_{Y} I} \\
\frac{b l^{2}}{2 c E_{Y} I} & \frac{d l^{3}}{3 c^{2} E_{Y} I}
\end{array}\right]\left[\begin{array}{c}
M \\
F
\end{array}\right] .
$$

Finally, by combining the partial results into (A2), the following inverse stiffness matrix is found (where $l$ is the total length of the reinforced plate spring).

The dimensionless coefficients $a, b, c$, and $d$ are given by the following:

$$
\begin{array}{rlrl}
a & =p-1, & \text { with } p & =\frac{l_{2}}{l} \\
b & =(p+1)(q-1)+2, & \text { with } q=\frac{l_{1}}{l_{3}} \\
c & =q+1 & \\
d & =a^{2}+c^{2}+p(p+1) q(q-1)+3 p q-1 .
\end{array}
$$

Inverting (A5) results in the stiffness matrix relating moment and force to deflection and angle as follows:

$$
\left[\begin{array}{c}
M \\
F
\end{array}\right]=-\frac{1}{a\left(4 d-3 b^{2}\right)}\left[\begin{array}{cc}
\frac{4 E_{Y} I d}{l} & \frac{-6 E_{Y} I b c}{l^{2}} \\
\frac{-6 E_{Y} I b c}{l^{2}} & \frac{12 E_{Y} I c^{2}}{l^{3}}
\end{array}\right]\left[\begin{array}{l}
\phi \\
f
\end{array}\right]
$$

\section{REFERENCES}

[1] B. R. De Jong, D. M. Brouwer, H. V. Jansen, M. J. De Boer, T. G. Lammertink, S. Stramigioli, and G. J. M. Krijnen, "A planar 3 DOF sample manipulator for nano-scale characterization," in Proc. 19th IEEE Int. Conf. MEMS, 2006, pp. 750-753.

[2] American Society for Precision Engineering. [Online]. Available: http:// www.aspe.net/

[3] A. H. Slocum, Precision Machine Design. Englewood Cliffs, NJ: Prentice-Hall, 1992.

[4] M. P. Koster, Constructie Principes voor het Nauwkeurig Bewegen en Positioneren. Twente, The Netherlands: Twente Univ. Press, 2000.

[5] N. Maluf, An Introduction to Microelectromechanical Systems Engineering. Norwood, MA: Artech House, 2000.

[6] D. M. Brouwer, B. R. De Jong, M. De Boer, H. V. Janssen, J. Van Dijk, G. J. M. Krijnen, and H. M. J. R. Soemers, "MEMS-based clamp with a passive hold function for precision position retaining of micro manipulators," J. Micromech. Microeng., vol. 19, no. 6, pp. $065027-065046$, May 2009.

[7] B. Jokiel, G. L. Benavides, L. F. Bieg, and J. J. Allen, "Planar and spatial three-degree-of-freedom micro-stages in silicon MEMS," in Proc. ASPE Annual Meeting, 2001, vol. 25, pp. 32-35.

[8] Y. Lu, C. K. Pang, J. Chen, H. Zhu, J. Q. Yang, G. Mou, B. M. Guo, and T. H. Lee, "Design, fabrication and control of a micro X-Y stage with large ultra-thin film recoding media platform," in Proc. IEEE/ASME Int. Conf. Adv. Intell. Mechatronics, 2005, pp. 24-28.

[9] J. Dong and P. M. Ferreira, "Electrostatically actuated cantilever with SOI-MEMS parallel kinematic XY stage," J. Microelectromech. Syst., vol. 18, no. 3, pp. 641-651, Jun. 2009.
[10] D. Mukhopadhyay, J. Dong, E. Pengwang, and P. M. Ferreira, "A SOIMEMS-based 3-DOF planar parallel-kinematics nanopositioning stage," Sens. Actuators A, Phys., vol. 147, no. 1, pp. 340-351, Sep. 2008.

[11] X. Lui, Y. Kim, and Y. Sun, "A MEMS stage for 3-axis nanopositioning," in Proc. 3rd Annu. IEEE Conf. Autom. Sci. Eng., 2007, pp. 1087-1092.

[12] E. Sarajlic, M. J. de Boer, H. V. Jansen, N. Arnal, M. Puech, G. Krijnen, and M. Elwenspoek, "Bulk micromachining technology for fabrication of two-level MEMS in standard silicon substrate," in Proc. Transducers, 2005, pp. 1404-1405.

[13] P. Liu, Y. Fang, and T.-F. Lu, "Classification and general kinematic models of 3-DOF planar parallel manipulators," in Proc. Comput.-Aided Ind. Des. Conceptual Des., 2006, pp. 1-6.

[14] O. Bochobza-Degani, D. Elata, and Y. Nemirovsky, "A general relation between the ranges of stability of electrostatic actuators under charge or voltage control," Appl. Phys. Lett., vol. 82, no. 2, pp. 302-304, Jan. 2003.

[15] D. Elata and V. Leus, "How slender can comb-drive fingers be?" J. Micromech. Microeng., vol. 15, no. 5, pp. 1055-1059, Apr. 2005.

[16] J. J. Wortman and R. A. Evan, "Young's modulus, shear modulus and poisson's ratio in silicon and germanium," J. Appl. Phys., vol. 36, no. 1, pp. 153-156, Jan. 1965.

[17] A. A. Kuijpers, "Micromachined capacitive long-range displacement sensor for nano-positioning of microactuator systems," Ph.D. dissertation, Twente Univ., Twente, The Netherlands, 2004.

[18] D. L. Blanding, Exact Constraint: Machine Design Using Kinematic Principles. New York: ASME, 1999.

[19] L. C. Hale, "Principles and techniques for designing precision machines," Ph.D. dissertation, Lawrence Berkeley Nat. Lab., Berkeley, CA, 1999.

[20] W. C. Young and R. G. Budynas, Roark's Formulas for Stress and Stain. New York: McGraw-Hill, 2002.

[21] R. Legtenberg, "Electrostatic actuators fabricated by surface micromachining techniques," Ph.D. dissertation, Twente Univ., Twente, The Netherlands, 1996, no 2 , pp. 43-46.

[22] D. M. Brouwer, "Design principles for six degrees-of-freedom MEMSbased precision manipulators," Ph.D. dissertation, Twente Univ., Twente, The Netherlands, 2007

[23] J. Van Eijk, "On the design of plate-spring Mechanisms," Ph.D. dissertation, Twente Univ. Press, Twente, The Netherlands, 1985.

[24] D. M. Brouwer, B. R. de Jong, and H. M. J. R. Soemers, "Design and modeling of a six DOFs MEMS-based precision manipulator," J. Precision Eng., vol. 34, no. 2, pp. 307-319, Apr. 2010.

[25] J. B. Jonker and J. P. Meijaard, "SPACAR—Computer program for dynamic analysis of flexible special mechanisms and manipulators," in Multibody Systems Handbook. Berlin, Germany: Springer-Verlag, pp. 123-143.

[26] E. Sarajlic, M. J. De Boer, H. V. Janssen, N. Arnal, M. Puech, G. J. M. Krijnen, and M. C. Elwenspoek, "Advanced plasma processing combined with trench isolation technology for fabrication and fast prototyping of high aspect ratio MEMS in standard silicon wafers," J. Micromech. Microeng., vol. 14, no. 9, pp. S70-S75, Aug. 2004.

[27] H. Jansen, G. Gardeniers, M. De Boer, M. Elwenspoek, and J. Fluitman, "A survey on the reactive ion etching of silicon in microtechnology," J. Micromech. Microeng., vol. 6, no. 1, pp. 14-28, Mar. 1996.

[28] A. R. Gottscho, C. W. Jurgensen, and D. J. Vitkavage, "Microscopic uniformity in plasma etching," J. Vac. Sci. Technol. B, Microelectron. Process. Phenom., vol. 10, no. 5, pp. 2133-2147, Sep. 1992.

[29] NI Vision Assistant 7.1. [Online]. Available: http://www.ni.com/pdf/ manuals/372228f.pdf

[30] Polytec. [Online]. Available: http://www.polytec.com/

[31] J. M. Gere, Mechanics of Materials. Pacific Grove, CA: Brooks/Cole, 2004.

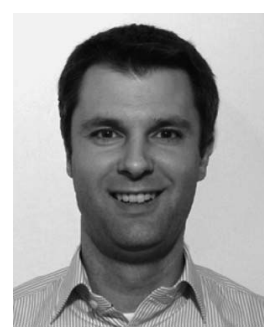

Boudewijn R. de Jong (S'02-M'07) received the M.Sc. degree in electrical engineering and the Ph.D. degree from the Faculteit Elektrotechniek, Wiskunde, en Informatica, University of Twente, Enschede, The Netherlands, in 2002 and 2006, respectively.

He is currently with Philips Applied Technologies, Eindhoven, The Netherlands, where he works in the Group of Electronic Packaging and Thin Film of the Department of System in Package. From October 2002 until October 2006, he worked on the Multiaxis Microstage Project at the University of Twente to receive his Ph.D. degree. This project was directed specifically at stable and accurate (nanometer resolution) multidegrees-of-freedom positioning with a microelectromechanical-systemsbased manipulator over typical strokes of $+/-10 \mu \mathrm{m}$. 


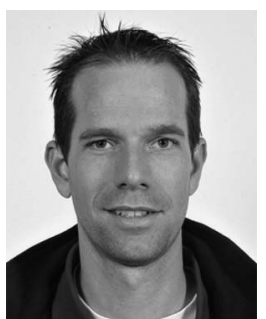

Dannis M. Brouwer received the M.Sc. degree in mechanical engineering from Eindhoven University of Technology, Eindhoven, The Netherlands, in 1998. He received a second M.Sc. degree in mechatronics design from Eindhoven University of Technology in 2001. From 2001 to 2004, he was with Philips Applied Technologies, Eindhoven, The Netherlands, as a Mechatronics System Designer. In 2007, he received the Ph.D. degree in mechanical engineering from the University of Twente, Enschede, The Netherlands.

$\mathrm{He}$ is currently an Assistant Professor at the University of Twente and a Senior Applied Research Engineer with Demcon Advanced Mechatronics. $\mathrm{He}$ is specialized in the design and modeling of complex mechatronic systems, such as flexure-based mechanisms and microelectromechanical systems.

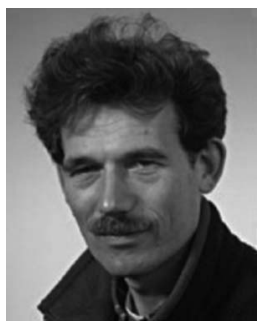

Meint J. de Boer was born in Hoornsterzwaag, The Netherlands.

He joined Sentron in 1982. As a Process Engineer, he worked in the field of $\mathrm{pH}$ and pressure sensors for medical applications. In 1988, he joined the Department of Applied Physics, University of Groningen, Groningen, The Netherlands, where he focused on nanoengineering for fundamental research on superconductivity. In 1992, he joined the Transducer Science Technology Group at the University of Twente, Enschede, The Netherlands. His current research interests include silicon micromachining and related fabrication techniques, with a focus on deep reactive ion etching techniques. He has published over 65 reviewed journal papers on micromachining and related topics and is the holder of five patent applications.

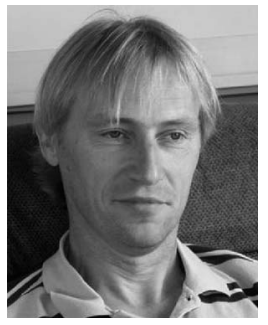

Henri V. Jansen received the M.Sc. and Ph.D. degrees in electronic engineering from the University of Twente, Enschede, The Netherlands, in 1991 and 1996, respectively.

After working for six months at the Centre Suisse d'Electronique et de Microtechnique, Neuchâtel, Switzerland, as a Plasma Engineer, he rejoined the Department of Electrical Engineering, University of Twente, as a Postdoctoral Fellow. In 2000, he joined the Interuniversity Microelectronics Center, Leuven, Belgium, to assist in the development of radio frequency microelectromechanical systems to be used in cellular phones. In September 2001, he became an Assistant Professor, and in 2004, he was promoted to Associate Professor in the Department of Electrical Engineering. His main research expertise is in silicon-based micromachining in general and plasma engineering in particular, with applications in the field of miniaturized sensor and actuator systems. His current major focus is directed toward nanofabrication for green energy and clean water and air.

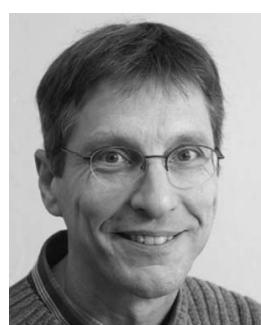

Herman M. J. R. Soemers received the M.Sc. degree in mechanical engineering from Eindhoven University of Technology, Eindhoven, The Netherlands, in 1983.

After serving as an Officer in the Royal Dutch Navy, he started his career at Philips Center for Industrial Technology (CFT), Eindhoven, The Netherlands (currently Applied Technologies), as a Development Engineer of Precision Engineering from 1984 to 1991 . From 1991 to 1997 , he was a Manager of Mechanization Modules at Philips CFT followed by a term as a Senior Scientist of Vacuum Stages from 1997 to 1999. From 1999 to 2000, he was a Manager of Semiconductor Equipment Research, and from 2000 to 2008, he was a Senior Mechatronics System Designer at Philips Applied Technologies. In 2002, he became a part-time Professor in the Group of Mechatronic Design, Department of Engineering Technology, University of Twente. Since 2008, he has been both a Manager of the System Architecture Group and a Technology Manager of Mechatronics at Philips Applied Technologies.

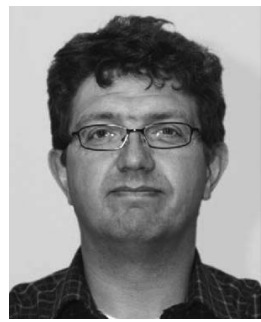

Gijs J. M. Krijnen (M'90) received the Doctorate degree with honors from the University of Twente, Enschede, The Netherlands, in 1992, and was awarded the 1993 Veder Prize of the Dutch Electronics and Radio Engineering Society for his $\mathrm{Ph} . \mathrm{D}$. thesis on nonlinear integrated optics devices. He received the M.Sc. degree in electrical engineering with honors from the same university following a study on oblique magnetic recording carried out at Philips Research Laboratories, Eindhoven, The Netherlands.

Since 1998, he has been an Associate Professor in the Transducers Science and Technology Group of MESA+, University of Twente, where he is responsible for microactuator research. From 1995-1997, he worked on integrated optic devices for optical telecommunication simultaneously with the University of Twente and Delft University of Technology, Delft, The Netherlands. He is currently the Chair of MEMS Design in the Electrical Engineering Department, University of Twente (since May 2007). His current interests are in lifelike MEMS in general and biomimetic flow-sensors in particular. In 2005, he was awarded a VICI Grant by the Netherlands Organization for Scientific Research for a five-year program on lifelike MEMS sensors (BioEARS). From 1992 to 1995, he was a Fellow with the Royal Netherlands Academy of Arts and Sciences and studied second- and third-order nonlinear integrated optics devices. In this period, he was a Visiting Scientist at the Center for Research and Education in Optics and Lasers in Orlando, FL. 